\title{
The Sensitivity of Land-Atmosphere Coupling to Modern Agriculture in the Northern Midlatitudes $\mathscr{O}$
}

\author{
SONALi SHUKLA MCDermid, ${ }^{\mathrm{a}, \mathrm{b}}$ CARLO MONTES, ${ }^{\mathrm{b}}$ BENJAMIN I. COOK,, $\mathrm{c}$ \\ MiChaEl J. Puma, ${ }^{\mathrm{b}, \mathrm{c}, \mathrm{d}}$ NANCY Y. KiAnG, ${ }^{\mathrm{b}}$ AND IGOR AlEINOV \\ ${ }^{a}$ Department of Environmental Studies, New York University, New York, New York \\ ${ }^{\mathrm{b}}$ NASA Goddard Institute for Space Studies, New York, New York \\ ${ }^{\mathrm{c}}$ Center for Climate Systems Research, Columbia University, New York, New York \\ ${ }^{\mathrm{d}}$ Center for Climate and Life, Columbia University, New York, New York
}

(Manuscript received 22 November 2017, in final form 14 September 2018)

\begin{abstract}
Modern agricultural land cover and management are important as regional climate forcings. Previous work has shown that land cover change can significantly impact key climate variables, including turbulent fluxes, precipitation, and surface temperature. However, fewer studies have investigated how intensive crop management can impact background climate conditions, such as the strength of land-atmosphere coupling and evaporative regime. We conduct sensitivity experiments using a state-of-the-art climate model with modified vegetation characteristics to represent modern crop cover and management, using observed crop-specific leaf area indexes and calendars. We quantify changes in land-atmosphere interactions and climate over intensively cultivated regions situated at transitions between moisture- and energy-limited conditions. Results show that modern intensive agriculture has significant and geographically varying impacts on regional evaporative regimes and background climate conditions. Over the northern Great Plains, modern crop intensity increases the model simulated precipitation and soil moisture, weakening hydrologic coupling by increasing surface water availability and reducing moisture limits on evapotranspiration. In the U.S. Midwest, higher growing season evapotranspiration, coupled with winter and spring rainfall declines, reduces regional soil moisture, while crop albedo changes also reduce net surface radiation. This results overall in reduced dependency of regional surface temperature on latent heat fluxes. In central Asia, a combination of reduced net surface energy and enhanced pre-growing season precipitation amplify the energy-limited evaporative regime. These results highlight the need for improved representations of agriculture in global climate models to better account for regional climate impacts and interactions with other anthropogenic forcings.
\end{abstract}

\section{Introduction}

Conversions of native vegetation to cropland and pasture, along with deforestation for both agriculture and timber-harvesting, have been the dominant driver of land surface change over the historical period (Ramankutty et al. 2002, 2006; Smith et al. 2014). Late twentiethcentury advances in mechanization and intensification have further augmented this global expansion of agriculture. These developments have facilitated the current

Supplemental information related to this paper is available at the Journals Online website: https://doi.org/10.1175/JCLID-17-0799.s1.

Corresponding author: Sonali Shukla McDermid, sps246@nyu. edu widespread use of improved crop varieties and an increased reliance on inputs (e.g., fertilizers, irrigation) to drive higher yields (Erisman et al. 2008; Foley et al. 2011). Besides enabling copious increases in food, fuel, and fiber production, modern agriculture is now also an important forcing on the climate system and environment. Agriculture accounts for nearly $30 \%$ of greenhouse gas (GHG) emissions and has substantially modified regional energy balance, moisture fluxes, natural biogeochemical cycling, and even larger-scale circulation patterns (Pongratz et al. 2008; Nair et al. 2011; Pielke et al. 2011; Gray et al. 2014; Tubiello et al. 2014; Zeng et al. 2014).

The cooling response to midlatitude land cover change has been well documented by both model and observational studies, and is primarily mediated by altered surface energy partitioning and/or changes in albedo and vegetation characteristics from natural land 
cover (Pielke et al. 2011; de Noblet-Ducoudré et al. 2012; Mahmood et al. 2014; McDermid et al. 2017; Diffenbaugh 2009; Gameda et al. 2007; Pitman et al. 2011). Additionally, modern agriculture may also play a role in attenuating regional heat extremes and modulating the annual temperature cycle (Mueller et al. 2016; Raddatz 2007). These responses have been attributed not just to land cover changes alone, but also to the intensification of cropping systems, including more productive varieties, higher planting densities, multiple crops within a year, and, in some cases, irrigation (Mueller et al. 2017; Georgescu et al. 2011; Ge 2010; Alter et al. 2017). Thus, the impacts of intensive agricultural land management may be equally important as, and may contrast with, those of land cover change alone (Luyssaert et al. 2014). The thermal effects of agricultural land management can be in fact so pronounced that recent works suggest it might be evaluated as a component of regional climate change mitigation (Seneviratne et al. 2018; Thiery et al. 2017; Hirsch et al. 2017).

Despite this previous work, more study is needed to understand how agricultural land use modifies regional hydroclimates and background climate conditions. Much uncertainty still exists regarding the impacts of agricultural land use on regional climate conditions such as evaporative regimes (energy- vs moisture-limited conditions) and land-atmosphere coupling strength (Lejeune et al. 2017; Hirsch et al. 2014, 2015). This coupling is largely modulated through soil moisture and is an important determinant of surface climate conditions from subtropical to midlatitude regions (Seneviratne et al. 2010). The strength of this coupling is also highly sensitive to evaporative regime and, in the model environment, to land surface model parameterizations, vegetation dynamics, and boundary layer schemes (Koster et al. 2006; Pitman et al. 2009).

Additionally, vegetation transitions, structure, phenology, and growth dynamics also play an important role in determining soil moisture-climate feedbacks, and thus land-atmosphere interactions and coupling strength (Seneviratne et al. 2010). Spatial and temporal vegetation changes alter transpiration contributions to the total latent heat flux, thereby impacting soil moisture and regional hydrology to modulate evaporative regimes (Dirmeyer et al. 2006). For example, Alessandri and Navarra (2008) showed that $\sim 12 \%$ of global precipitation variability is forced by changes in vegetation features, which can amplify or detract from modes of natural climate variability. A novel study by Hirsch et al. (2014) applied methods of quantifying climate model land-atmosphere coupling (Koster et al. 2006; de Noblet-Ducoudré et al. 2012) to simulations of land cover change in Australia. They found that where crops replaced forested areas, the resulting leaf area index (LAI) changes significantly reduced the landatmosphere coupling strength (Hirsch et al. 2014).

However, few such studies have been conducted for intensive midlatitude growing regions, which constitute some of the most productive agricultural lands, spanning strong gradients in evaporative regime, and display significant temporal climate variability (Seneviratne et al. 2006, 2010; Ryu et al. 2008; Mueller et al. 2012). Yet, these previous findings have important implications for midlatitude hydroclimatic regimes, where intensive agriculture may potentially alter and interact with rainfall, soil moisture, and water availability. Such interactions may even feed back to change the regional climate suitability upon which these productions systems rely. These implications are particularly salient to agricultural adaptation, for as much as $\sim 25 \%$ of midlatitude yield variability has been attributed to variations in hydroclimate conditions (Ray et al. 2015). There is therefore an outstanding need to better evaluate the impacts of modern, intensive agricultural management on landatmosphere coupling and hydroclimate conditions for key midlatitude growing regions.

To meet this need, we present results from a set of unique global climate model (GCM) sensitivity experiments using a prescribed global representation of modern intensive agriculture. This representation uses cropping calendars (planting and harvest dates) and regionally representative leaf area index for maize, rice, wheat, and soybean to reflect the modern intensity of agriculture through crop growth and timing, multicropping, and/or crop rotations. We evaluate how the resulting changes in soil moisture and key surface climate variables affect the evaporative regime and hydrologic coupling between the land surface and atmosphere across important midlatitude growing regions of the Northern Hemisphere between $35^{\circ}$ and $55^{\circ} \mathrm{N}$. We place particular emphasis on the simulated impacts along transitions zones between moisture- and energy-limited conditions, and further elucidate how modern agriculture has shaped regional climate conditions.

\section{Methods and experiments}

\section{a. The NASA GISS ModelE GCM}

We use an updated and improved version of the NASA Goddard Institute for Space Studies global climate model (ModelE), which utilizes vegetation characteristics from the Ent Terrestrial Biosphere Model (Ent TBM). ModelE is a state-of-the-art Earth system model (ESM) that contributes to the Coupled Model Intercomparison Project (Eyring et al. 2016) as an 
ongoing development effort, with the most recent documented version described in Schmidt et al. (2014), Miller et al. (2014), and Nazarenko et al. (2015). ModelE runs at $2^{\circ} \times 2.5^{\circ}$ spatial resolution with 40 vertical layers in the atmosphere, where resolution is enhanced between $825 \mathrm{hPa}$ and the tropopause. We utilize the prescribed ocean version to evaluate equilibrated, climatological terrestrial surface-atmosphere dynamics. ModelE has been shown to reasonably represent observed climate conditions and responses to historical anthropogenic forcings (Schmidt et al. 2014; Miller et al. 2014), albeit with some outstanding biases. These include warm and dry biases over South Asia and cool and wet biases over the midlatitudes, as well as cool biases in the upper troposphere. However, we do not expect these biases to significantly impact our experimental results or findings. Each experiment was run with the same process configurations, and the anomalies and hydroclimatic changes produced are attributable to and representative of our implemented agricultural land forcing (described below).

The Ent TBM is a dynamic global vegetation model designed for coupling with ESMs, in this case ModelE and its land surface model. While ongoing Ent development will enable fully coupled, dynamic vegetation simulations, in the current study we operate Ent in "biophysics-only" mode, as described by Kim et al. (2015). In this mode, water vapor fluxes are prognostically simulated for each grid box by a prescribed canopy structure and maximum and minimum LAI, which are given for 17 possible plant functional types (PFTs). Further details about the natural vegetation phenology can be found in Kim et al. (2015) and about canopy radiative transfer in Friend and Kiang (2005).

The Ent TBM is forced by atmospheric and land surface variables obtained from ModelE and the embedded LSM. Canopy radiative transfer is parameterized for homogeneous canopies by the approach of Spitters et al. (1986) to estimate the radiation profile for sunlit and shaded fractions in numerically solved foliage layers, while vegetation albedo is prescribed per extrapolations from the Matthews (1983) vegetation cover classifications (Friend and Kiang 2005). ModelE's land surface module explicitly solves for soil and canopy temperature by calculating change in heat content, following the formulations in Rosenzweig and Abramopoulos (1997). The land surface model computes the average ground temperature for each time step and passes it to the atmospheric surface routine of the GCM, which then returns the corresponding drag coefficient and air surface temperature to the land surface module (Rosenzweig and Abramopoulos 1997). Latent heat fluxes from the surface are separated between the vegetated and nonvegetated portions of the grid cell. For vegetated fractions, the evapotranspiration (ET) term is the sum of four components: transpiration, canopy evaporation, vegetated soil evaporation, and snow evaporation. Potential transpiration follows an aerodynamic formulation specified in Hansen et al. (1983) and Rosenzweig and Abramopoulos (1997), which is dependent on canopy conductance, atmospheric conductance, and the saturated and unsaturated air humidity. For soil evaporation under the canopy, a modification is made to the turbulent transfer coefficient to account for wind/leaf interactions. For the bare soil fraction of the grid cell, evaporation occurs as the minimum of the Penman potential evaporation or Gardner-Hillel diffusivity Abramopoulos et al. (1988). Wet, nontranspiring canopies are assumed to evaporate at the potential rate.

In general, the ModelE geographic distribution of evaporative regimes-that is, energy- versus moisturelimited regions such as those described by Koster et al. (2009) and Seneviratne et al. (2010) — compare well with observations (see Fig. S1 in the online supplemental material), although the model underpredicts the geographic prevalence of the most energy-limited domains.

\section{b. Adapting global datasets to represent intensive agriculture}

For natural vegetation, ModelE utilizes a vegetation map derived from MODIS data for climatological simulations (N. Kiang et al., unpublished manuscript), and monthly prescribed values from the MODIS (MOD15A2 V004, L4) LAI product (Tian et al. 2002a,b; Yang et al. 2006) assigned to subgrid cover fractions of Ent PFTs. The MODIS (MCD12Q1 V005 L3) International Geosphere-Biosphere Program (IGBP) land cover and MODIS plant functional types for the year 2004 (Friedl et al. 2010) were classified into Ent PFTs, utilizing additional data on forest heights (Simard et al. 2011) and climate (Schneider et al. 2014; Harris et al. 2014). The MODIS monthly LAI of the same year was then assigned to the corresponding PFTs in the pixel. For climatological or historical ModelE simulations using natural vegetation only, the crop fraction and crop LAI were removed and the remaining natural Ent PFT cover was up-scaled so that all types sum to one in the grid cell, creating all-natural vegetation PFT and LAI maps. For grid cells that were lacking natural vegetation types, the natural cover and LAI from the adjacent cells was interpolated. This classification was then aggregated for the ModelE resolution. Aggregating the MODIS natural vegetation types for use with Ent PFTs at the ModelE $2^{\circ} \times 2.5^{\circ}$ resolution does attenuate the extreme regional values, as many cells have either relatively low LAIs, or higher LAIs but with relatively low areal coverage. Within the model simulations, the 2004 MODIS 
monthly-prescribed LAIs are linearly interpolated to create a daily time series.

For experiments with crops, we leverage the global distribution of general crop and pasture coverage given by Pongratz et al. (2008) and Hurtt et al. (2011). These datasets contain crop and pasture cover for every 50 years from 800 to 1850 , for each decade between 1850 and 1980 , and then annually from 1986 to present. We run our experiments using this coverage for the year 2000 only (i.e., not time varying). To accommodate crop and pasture cover, natural vegetation and bare soil cover are rescaled proportionally with the crop cover PFT each year so that all cover fractions sum to one in a grid box. We then represented an annual crop phenological cycle in select grid boxes by merging three datasets (also centered on the year 2000): 1) a global map of crop-specific distributions from Monfreda et al. (2008), 2) a global map of planting and harvest dates for specific crops from Sacks et al. (2010), and 3) LAI from the MODIS-derived LAI3g product created by Zhu et al. (2013). Our approach was to quantify the timing of these crop varieties at a fine spatial resolution and then scale up their merged behavior into one crop cover type at the GCM grid box scale.

The Monfreda et al. (2008) dataset provides $5^{\prime} \times 5^{\prime}$ spatial resolution area fractions for 175 crops based on census statistics and crop maps globally. In the present work, we focus on four of the most globally prevalent crop types: maize, wheat (spring and winter), rice, and soybean (Ray et al. 2013). Some of these share a cultivated area during the growing season or are cropped in rotation with each other, both of which are forms of agricultural intensification. We first interpolated the Monfreda dataset to $50-\mathrm{km}$ resolution using a nearest neighbor approach and selected grid boxes where the crop-specific coverage was at minimum $15 \%$. Doing so minimizes the effects of highly heterogeneous cropping systems, which may contain crops for which we are unable to obtain a representative LAI signal (detailed below). A map of the specific cropped grid boxes that were altered with this "crop-specific" approach is shown in Fig. 1a.

The Monfreda et al. (2008) dataset is also used as the basis for global crops distribution in the Sacks et al. (2010) dataset, which describes the global distribution of crop-specific planting and harvest dates for 19 crops (totaling $71 \%$ of the global cropped area). This also ensures consistency in our approach between the crop type and planting/harvest dates within a specific grid box. These dates can vary geographically even for the same crop species, as they reflect regional patterns of solar radiation, rainfall and soil moisture, and thermal regime, while also acknowledging that the spatial distribution of planting and harvest dates are not solely due to climatic constraints (Sacks et al. 2010). Using
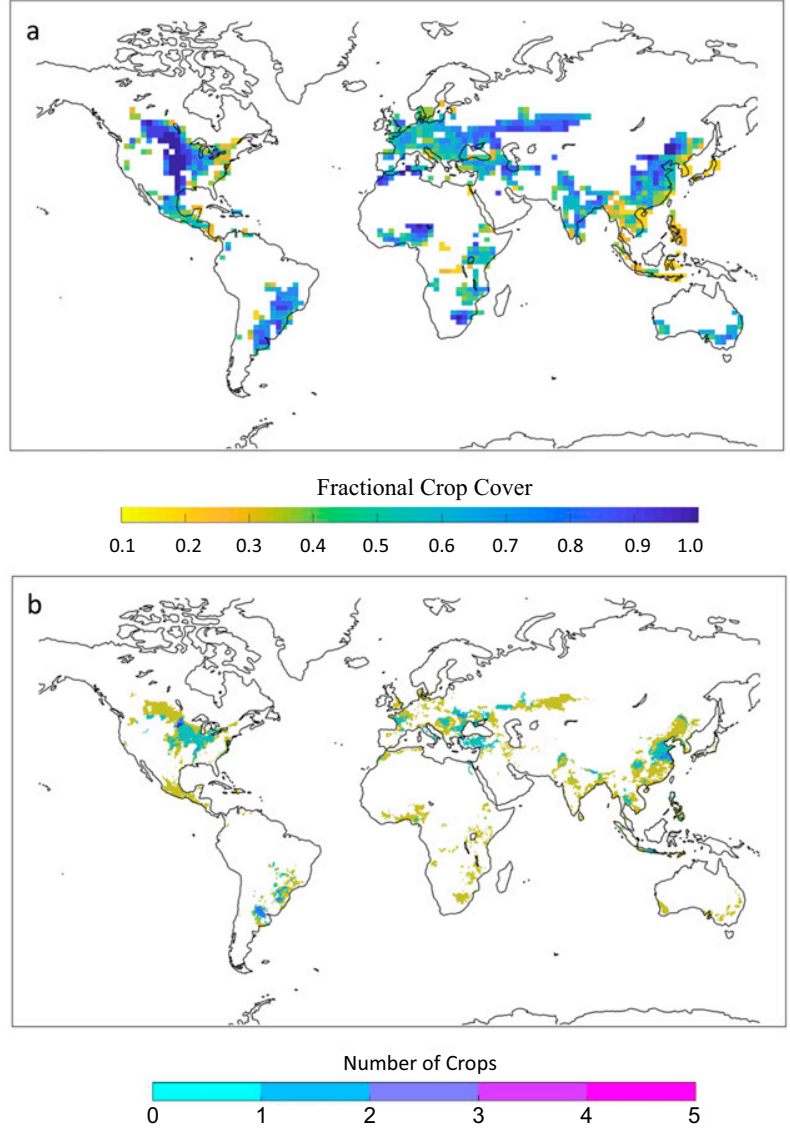

FIG. 1. (a) Fractional crop coverage shown at the native model resolution of $2^{\circ}$ latitude $\times 2.5^{\circ}$ longitude. (b) The number of crop cycles represented in each of the modified grid boxes, shown at the $0.5^{\circ}$ resolution of the Sacks et al. (2010) dataset. Grid boxes may contain more than one crop, and in some cases, such as the U.S. Midwest, many boxes represent a rotation between crops. The resulting LAIs are aggregated to ModelE resolution using the methods described herein

the Sacks et al. dataset at $50-\mathrm{km}$ resolution, we obtained the planting and harvest dates (in Julian day) for each of the crop-specific grid boxes identified in the Monfreda et al. dataset.

Using the above distributions for each crop variety, the respective LAI was then obtained from the Zhu et al. (2013) LAI3g product to reflect modern growth cycles. This product combines the MODIS MCD12C1 LAI, the Global Inventory Modeling and Mapping Studies (GIMMS) Advanced Very High Resolution Radiometer (AVHRR) NDVI (NDVI3g), and the MODIS-based Beijing Normal University LAI of Yuan et al. (2011) to generate a biweekly $1 / 12^{\circ} \times 1 / 12^{\circ}$ spatial resolution LAI for the period 1981-2011. We then identified major agricultural regions for each of the four crops: maize in the U.S. Midwest, Mexico and Central America, Brazil, South Africa, the Sahel, eastern Europe, and eastern China; soybean in the Midwest, Brazil, and Argentina; wheat in 
TABLE 1. Summary of ModelE experiments and land cover conditions.

\begin{tabular}{|c|c|c|c|}
\hline Experiment name & LAI evolution and maximum & Crop coverage & Planting/harvest dates \\
\hline NatVeg & $\begin{array}{l}\text { Interpolated daily from monthly default/ } \\
\text { generic MODIS MOD15A2 V005, L4, } \\
\text { LAI }\end{array}$ & None & - \\
\hline CropSpec & $\begin{array}{l}\text { Prescribed idealized green-up and } \\
\text { harvest, with maximum from LAI3g, } \\
\text { (Zhu et al. 2013) }\end{array}$ & $\begin{array}{l}\text { Monfreda et al. (2008), selected for maize, } \\
\text { wheat, rice, and soybean at } \geq 0.2 \\
\text { fractional coverage }\end{array}$ & Sacks et al. (2010) \\
\hline
\end{tabular}

the North American Great Plains, the Mediterranean, central Asia, northwestern South Asia, eastern China, and eastern Australia; and rice in South Asia, eastern China, and Indonesia. For each crop in each of these regions, we obtained the spatial, 1981-2011 annual average and standard deviation of the maximum annual LAI. We then take the spatial mean of the maximum LAI as a characteristic crop-specific "maximum" for the region (noting the extent of variation). In regions with highly varying LAI, multiple maxima could be considered "characteristic" for different sets of grid boxes. However, we did not stratify our regional grid boxes into different maxima at this time. One limitation this introduces is that the characteristic regional maximum LAI values are taken for mostly cropped areas, which are usually highly productive. As such, this characteristic maximum might overestimate the LAI in areas with lower productivity or highly heterogeneous growing regions. An example of this is the LAI values across Africa, which are largely informed by commercial production zones (mostly maize) in parts of South Africa.

Seasonal crop-specific LAI time series were generated following an idealized piecewise evolution: a sigmoidal curve was fitted from the corresponding planting date until the regionally characteristic maximum value; the maximum LAI is then sustained until the harvest date, after which the LAI drops to zero. Given that the planting and harvest dates vary spatially, the crop-specific LAI development therefore varies spatially as well. Currently, the date at which the crop achieves its maximum LAI is taken as the midpoint of the growing season window defined by the planting and harvest dates. As this method is further developed, the time between the planting date and maximum LAI may be determined by imposed "rules" based on the prevailing knowledge of crop development. However, imposing such rules is beyond the scope of the current study.

The daily LAI needed to be merged for each cropped grid box that contained more than one crop, as it is possible to have multiple crops occupy the same grid box on a given day. However, we have not yet currently utilized all possible crop types within the crop-fraction dataset. This presents a challenge for ascertaining appropriate and representative crop type-fractions within the grid box total cropped-fraction. As such, the crop type-fractions were equally partitioned among the number of crops in each grid box (the maximum being the five; see Fig. 1b, where spring and winter wheat are differentiated), such that the total type-fractions summed to one. We then merged the finer-scale crop types into one crop cover for each grid box, calculating the daily crop LAI using the weighted average of all present types.

The final model-ready LAI files were generated by aggregating the daily LAI to the native ModelE $2^{\circ} \times 2.5^{\circ}$ resolution, preserving the total LAI value for the merged crop cover in each grid box. The resulting grid box LAI is the cover-weighted average of the merged crops' LAI and all other vegetation covers. While similar implementations of crop calendars exist in other ESMs, to our knowledge this assessment is the first to bracket the regional climate sensitivity by including crop timing and seasonality.

\section{c. Experiment description}

We performed two sensitivity experiments: one experiment using natural vegetation land cover and attributes ("NatVeg"), and another experiment run with regional crop-specific coverage, planting/harvest dates, and altered maximum LAI to reflect maize, wheat, rice, and soybeans ("CropSpec"). These experiments are summarized in Table 1. We note that the NatVeg experiment does not represent simulated "potential vegetation" conditions, but rather reflects an up-scaling of the existing natural vegetation types from the MODIS product after removing crop and pasture lands (described above). Although the above-described representation is globally implemented, we herein constrain our analyses to Northern Hemisphere midlatitude growing regions, which are both highly productive and display large changes between energy and moisture limitation.

Both experiments utilized prescribed, climatological preindustrial (1876-85) sea surface temperatures, as well as preindustrial greenhouse gas forcings $\left(\left[\mathrm{CO}_{2}\right]=\right.$ $285.2 \mathrm{ppm})$, and we ran each simulation for 110 years. We nominally selected the last 50 years for both climatology and time series comparisons. Unless otherwise specified in our results section (section 3), a Student's $t$ test was used to assess our results' significance with the sample size modified for temporal autocorrelation following the methods of Zwiers and von Storch (1995). 
Leaf Area Index for Natural Vegetation
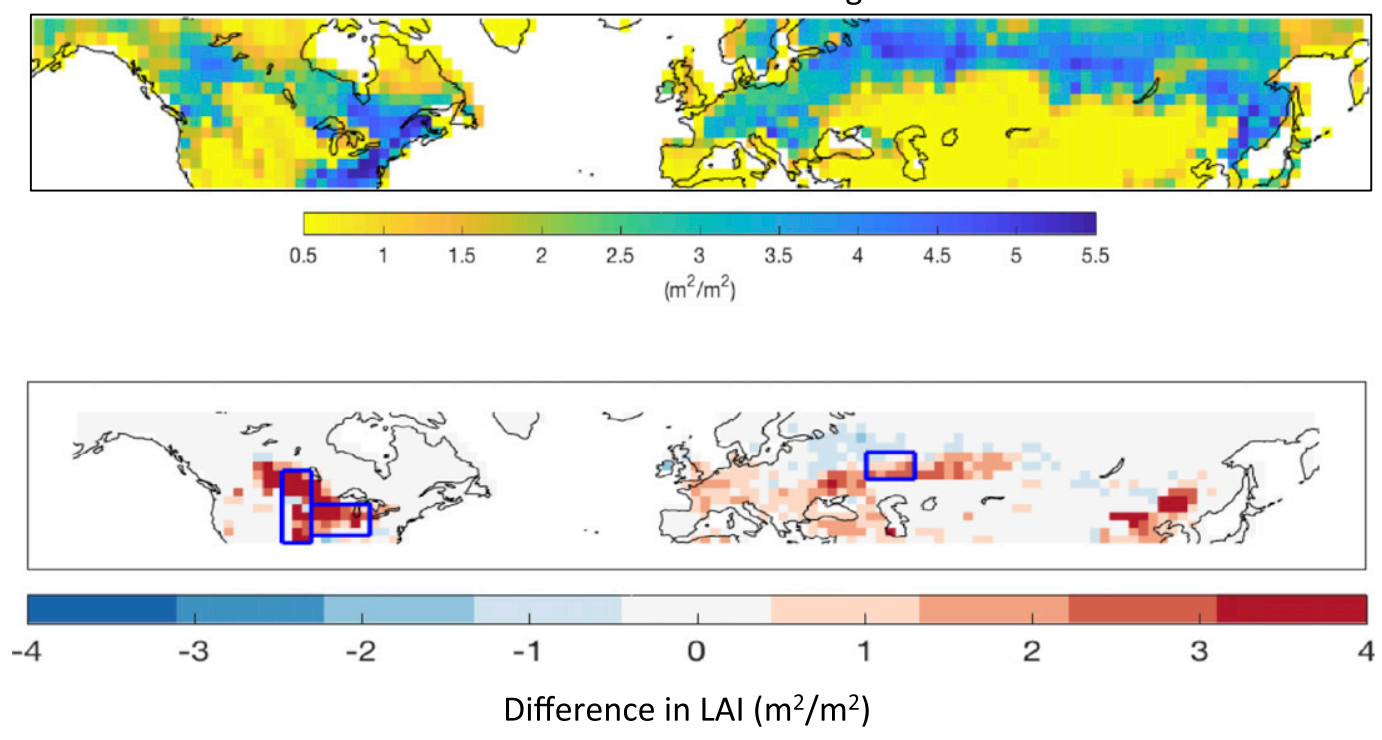

FIG. 2. (a) Maximum annual LAI for the NatVeg experiment. (b) The change in maximum LAI between the CropSpec and NatVeg experiments. The blue boxes denote the domains of focus: (i) the Great Plains, (ii) the Midwest, and (iii) central Asia.

Figure $2 \mathrm{~b}$ shows the difference in annual maximum LAI between our CropSpec and NatVeg experiments, which has increased across our three Northern Hemisphere agricultural regions of focus (boxed areas shown for June-August). Thus, in considering the resulting changes to important climate variables, landatmosphere interactions, and evaporative regime, we do so under the condition that LAI has increased across all analyzed grid boxes. We note that while some NatVeg peak LAI values may be attenuated by up-scaling to the model resolution from MODIS, the relative LAI differences between cropped and naturally vegetated areas in our domains compare well to same differences (cropped vs natural vegetation) taken for the MODIS product land cover and LAI.

LAI increases are prevalent across all three regions (Fig. 2b) due to modern agricultural intensification, which includes multiple crops, heightened planting densities, and improved varieties. It is also important to note that different natural vegetation types are present across these growing regions, which may modulate the resulting impacts. For example, the LAI increases are most prevalent in the Great Plains, which is dominated by $\mathrm{C} 3$ and $\mathrm{C} 4$ grasslands (LAI $=\sim 1$ for both PFTs) with smaller areas of deciduous broadleaf (mean PFT LAI $=$ 1.5) under NatVeg conditions. Increases are also visible in the U.S. Midwest, where NatVeg conditions were predominantly deciduous, broadleaf woodlands (mean PFT LAI $=\sim 3$ ), and in southern central Asia where C3 grasses dominate (mean PFT LAI $=\sim 1.5$ ) In the northern central Asia domain, however, crops replaced cold-adapted broadleaved trees (mean PFT LAI $=\sim 4$ ) and evergreen needleleaf (mean PFT $=\sim 2$ ), resulting in a slightly reduced LAI. Because of possible multicropping in some grid boxes (insofar as the four crops we included), the annual time evolution of crop LAI can display more variability and multiple modes. For example, there is an overlapping period in the growing seasons for different crops in the Midwest, leading to nonzero LAI values after a particular crop has been harvested. In addition, the co-occurrence of natural vegetation and crops in some grid boxes may also result in nonzero LAI pre-planting or post-harvest. In these grid boxes, it is possible that the annually averaged crop LAI will be lower than that of the natural vegetation, as the crop LAI goes to zero part of the year despite being higher during the growing season. This is particularly true for regions with shorter growing seasons.

\section{Results and discussion}

We examine three key midlatitude growing regions, based on their high agricultural productivity and intensity and their geographic location in transition zones between moisture- versus energy-limited evaporative regimes: the U.S. Great Plains, the U.S. Midwest, and central Asia.

Figure 3 shows the relationship between soil moisture and latent heat flux (LE) over the selected region, together with the correlation between LE and surface air temperature $[r(\mathrm{LE}, T)]$. This latter diagnostic serves as a 

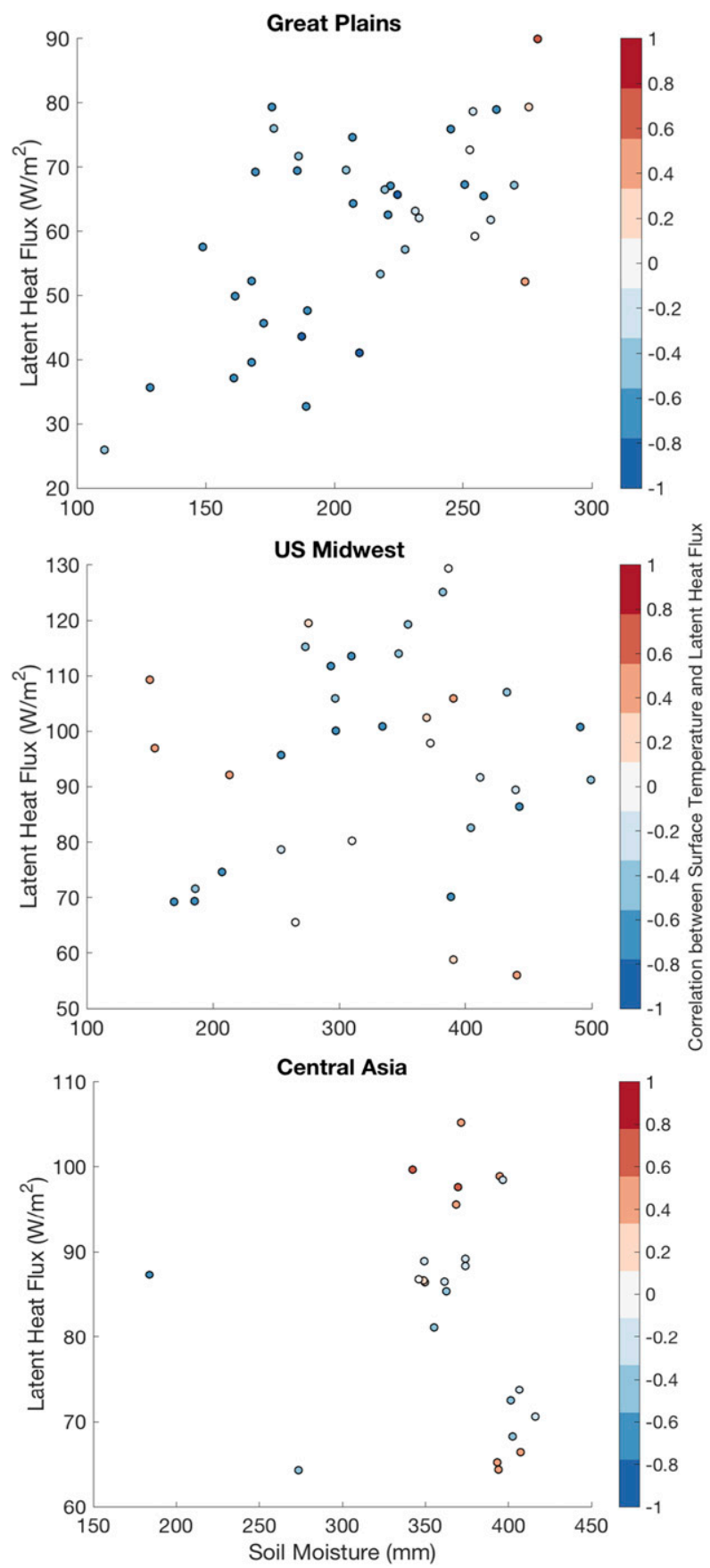

FIG. 3. June-August latent heat flux $\left(\mathrm{W} \mathrm{m}^{-2}\right)$ regressed against soil moisture in the top $50 \mathrm{~cm}$ of the soil column. Colors show the correlation between latent heat flux and surface temperature-a measure of the land-atmosphere coupling. Blue colors indicate negative correlations while red colors show positive correlations. Plots are shown for grid boxes lying within the outlined (a) Great Plains, (b) Midwest, and (c) central Asia domains.

general measure of the type (moisture- vs energy-limited) and the strength of evaporative regime, as mediated through regional surface water availability and general patterns net surface radiation (Seneviratne et al. 2006,
2010). As such, we hereafter refer to $r(\mathrm{LE}, T)$ as the hydrologic coupling strength between the land surface and atmosphere. All three regions discussed are important transition zones between moisture and energy limited conditions. For example, in the Great Plains (Fig. 3a), low levels of LE are related to low levels of soil moisture and water availability. These grid boxes also display a dominant negative relationship (blue colors) between LE and air temperature, which is evidence of how soil water can modulate surface air temperature. As soil moisture increases, the hydrologic coupling weakens until soil moisture no longer becomes the dominant driver of surface air temperatures, which are instead more closely related to the degree of energy limitation (red colors).

Figure $3 b$ shows a much weaker relationship over the Midwest between LE and soil moisture, in which some grid boxes show weakly negative $r(\mathrm{LE}, T)$ and others show weakly positive relationships. These characteristics indicate that the region is neither strongly water nor energy limited, and thus neither is the dominant driver of surface air temperatures. Figure $3 \mathrm{c}$ displays overall weaker relationships between LE and soil moisture in central Asia. Given the relatively high-latitude locus of this growing region, there exists a northward transition to stronger positively correlated grid boxes and energylimited evaporative regime (discussed in more detail in section $3 \mathrm{c}$ below).

The prevailing area-averaged responses of key surface climate variables are discussed in section $3 \mathrm{a}$ (Figs. 4-6) for each of the outlined domains in Fig. 2b. However, there also exist spatial variations that are not captured in the averaging and will be discussed in sections $3 \mathrm{~b}-3 \mathrm{~d}$ below. Unless otherwise specified, all maps and plots are shown for the prime growing season in the Northern Hemisphere, defined here as JuneAugust (JJA).

\section{a. Regionally averaged responses in key climate variables}

\section{1) U.S. GREAT Plains}

Since the early twentieth century, much of the Great Plains region has been under intensive cultivation, either in the form of livestock grazing or wheat production. The seasonal total LAI changes shown in Fig. 4a are dominated by the change in cropped area, and reflect the supplanting of the regional perennial grasses by wheat. Figure 4 also shows the monthly annual cycle of LE, precipitation, soil moisture, sensible heat flux, and the change in air temperature for the two experiments. LAI increases during the growing season enable significantly increased summer and autumn LE (Fig. 4b). Latent heat 


\section{Great Plains}
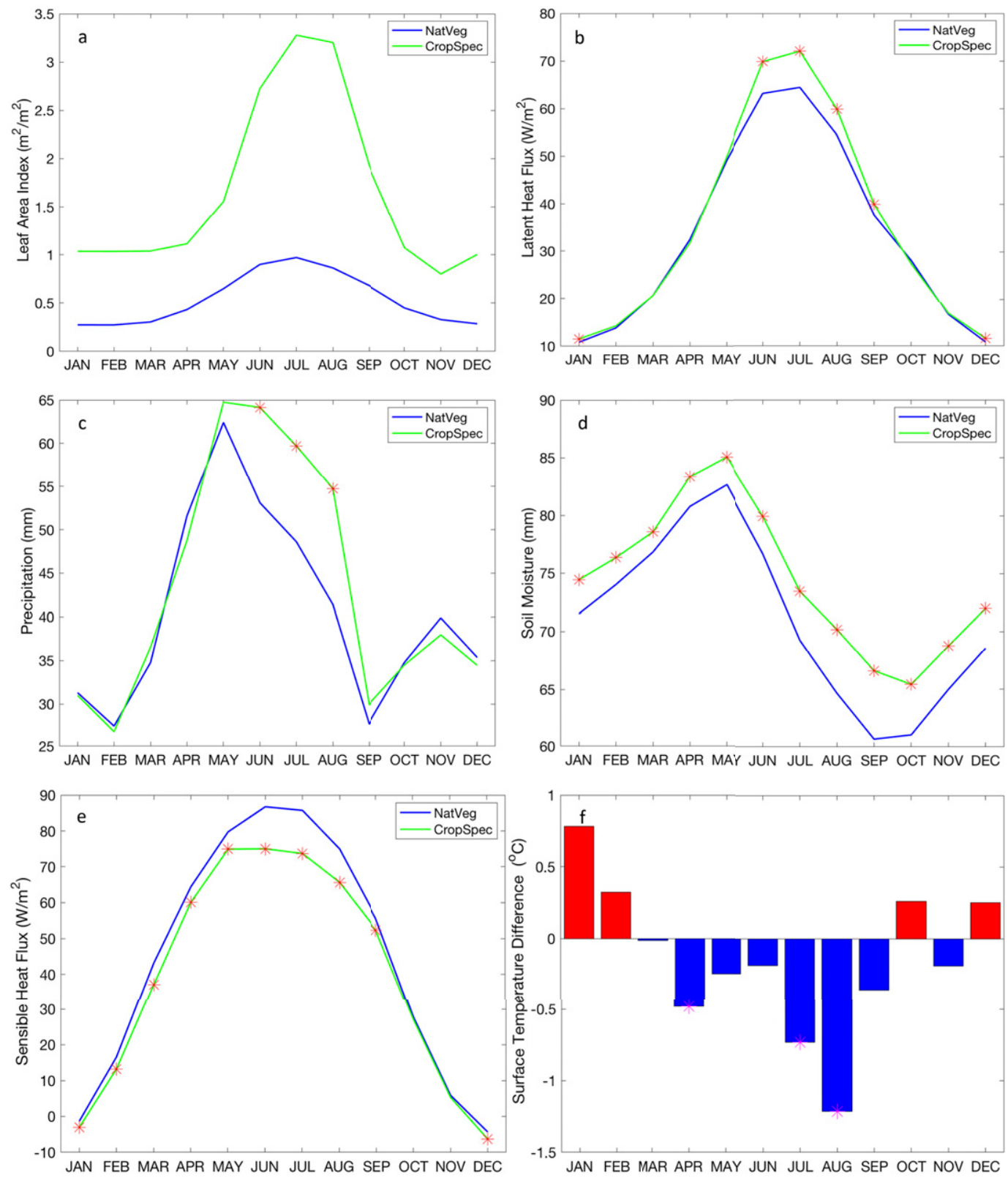

FIG. 4. Monthly average values over the Great Plains domain for (a) LAI, (b) latent heat flux (W m ${ }^{-2}$ ), (c) total precipitation $(\mathrm{mm}),(\mathrm{d})$ soil moisture in the top $50 \mathrm{~cm}$ of the soil column $(\mathrm{mm})$, and (e) sensible heat flux $\left(\mathrm{W} \mathrm{m}^{-2}\right)$ and (f) the difference in surface temperature between the CropSpec and NatVeg experiments. Pink stars indicate the statistical differences between both experiments for a specific month, following a modified Student's $t$ test.

fluxes are also reduced during the pre-planting period in the late spring, although these changes are relatively small. The growing season also exhibits significant increases in precipitation (Fig. 4c), which may facilitate the significantly enhanced soil moisture (Fig. 4d) over the whole year. Figure $4 \mathrm{e}$ shows that sensible heat flux decreases during the growing season when latent heat flux increases, indicating a seasonal change in the partitioning of incoming energy that is also reflected in the decrease in surface air temperature, particularly in July and August.

\section{2) U.S. MIDWEST}

LAI changes in the Midwest (Fig. 5a) reflect the supplanting of broadleaved woodlands with rotations of maize and soybean. These areas are some of the most 


\section{US Midwest}
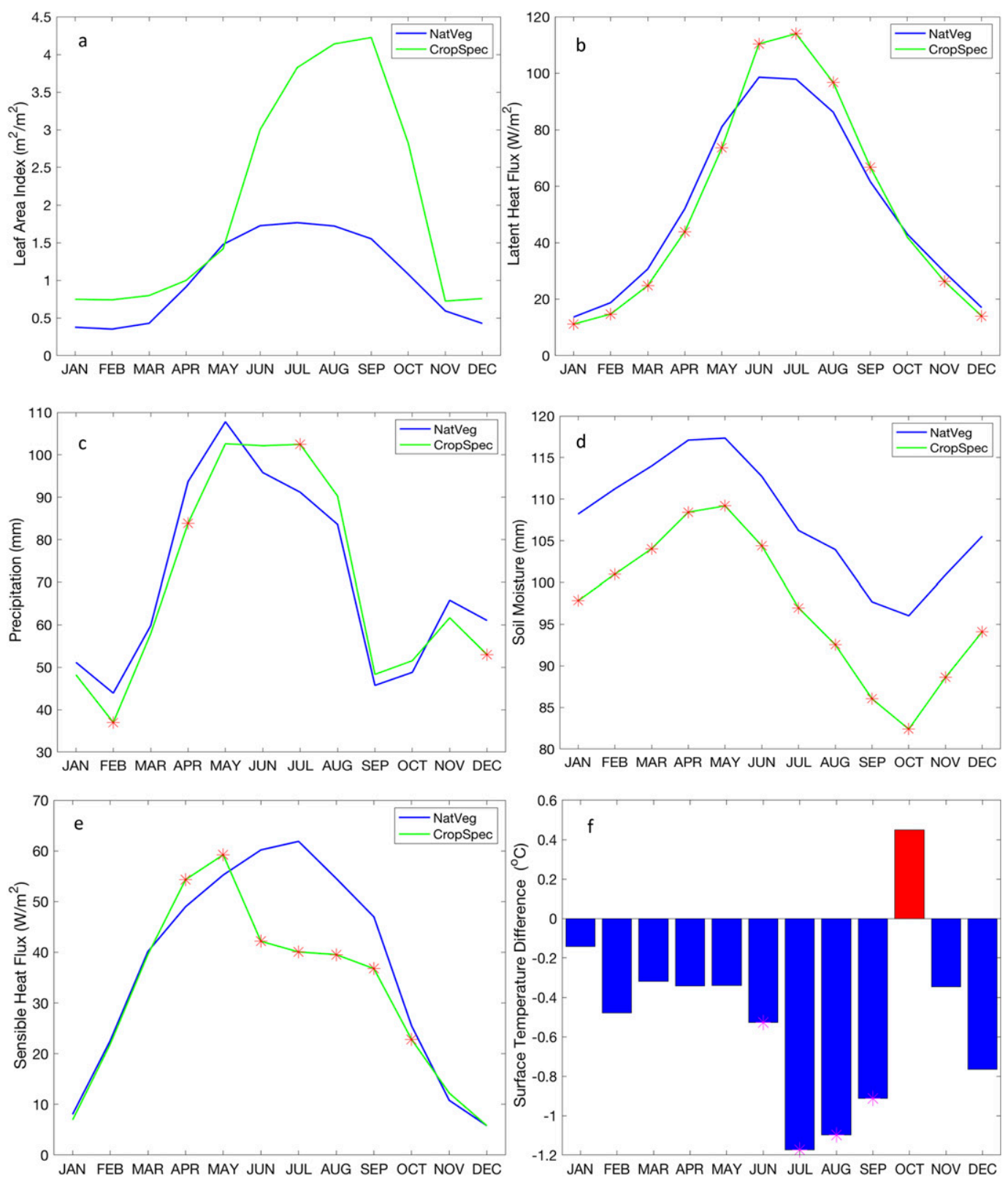

FIG. 5. As in Fig. 4, but for the Midwest domain.

intensively cultivated in the United States, with high planting densities (leading to relatively high LAIs), improved crop varieties, and inputs. Figure 5a shows LAI reductions during the springtime (pre-planting) period, and a rapid "green-up" follows thereafter to the peak growing season values. Reflecting these LAI differences, latent heat fluxes (Fig. 5b) are also significantly diminished during the planting period, increasing over the growing period and remaining relatively high into the early autumn upon harvest. While most months show no significant changes in precipitation (Fig. 5c), there is a change in the shape of the annual cycle, with an earlier peak for the CropSpec experiment that is likely associated with contemporaneous increase in LE, and the significant, albeit weak, reductions in December, February, and April. The later reductions coincide with relative declines in CropSpec LAI and latent heat fluxes. 


\section{Central Asia}
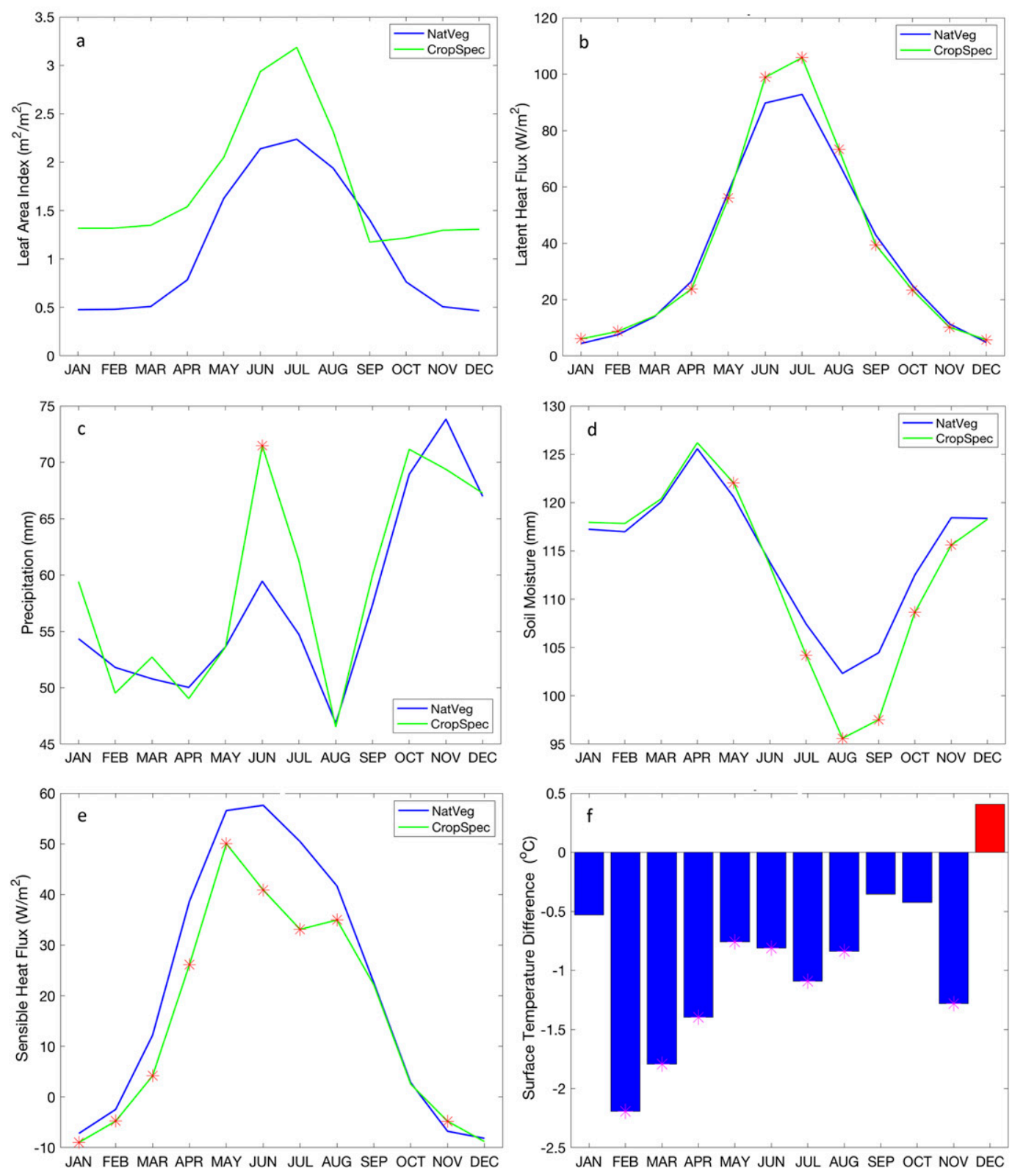

FIG. 6. As in Fig. 4, but for the central Asian domain.

Unlike the Great Plains, soil moisture is reduced throughout the year (Fig. 5d).

During the peak growing season, significant enhancements in latent heat fluxes (i.e., evapotranspiration) contribute to substantial soil moisture losses, while changes in precipitation and runoff (Fig. S2) are either small or not significant. However, precipitation is significantly reduced during some winter and spring months, which may contribute to maintaining the negative soil moisture anomalies throughout the year. The CropSpec experiment shows increased sensible heat fluxes in the spring (Fig. 5e), with significant declines from June through October when latent heat fluxes are higher. As in the Great Plains, this suggests a shift in summertime surface energy partitioning enabling a higher regional evaporative fraction. While air temperature reductions result throughout the year, significant responses occur primarily during the growing season and reflect the higher evaporative fraction under CropSpec conditions. 


\section{3) Central Asia}

Similar to the Great Plains, central Asian changes in LAI are primarily indicative of wheat cultivation in this region. In the most northern areas of the domain, where wheat cultivation has replaced cold-adapted forests, there is a limited area of LAI declines. Crops have replaced grasslands in most other parts of the domain. The CropSpec experiment shows area-averaged increased LAI for the growing season (Fig. 6a), except in the postharvest period. Despite these LAI increases, LE (Fig. 6b) is only increased substantially during a portion of the growing period, July-September, whereas spring and late autumn show very slight declines and little overall change. June is the only month that exhibits significantly increased precipitation, but this does not serve to significantly enhance soil moisture across the year (as seen in the Great Plains). Instead, the overall negligible change in rainfall combined with heightened growing season latent heat fluxes serve to significantly decrease soil moisture later in the growing season and into the fall from July to November, with little change occurring during the other months (Fig. 6d).

Soil moisture does, however, exhibit a small but significant increase during the May planting period. This is due in part to enhanced CropSpec regional snowfall (not shown) that boosts soil moisture during the planting period. Sensible heat fluxes are reduced for most months (Fig. 6e), most significantly during June-September. Springtime declines in both sensible and latent heat fluxes suggest that less energy is available for partitioning at the surface when compared to the NatVeg experiment. This substantial repartitioning of the surface energy balance partly drives the significantly reduced surface air temperatures during the spring months and over the growing season.

\section{b. Spatial variations in the responses of key climate variables and soil moisture}

Figure 7 shows the difference in the shortwave and longwave components of the net radiation between the experiments. There are slight, but significant, reductions in the incident shortwave radiation over southern areas of the central Asian domain (Fig. 7a). Together with the increased upward shortwave radiation (Fig. $7 b$ ), this reduces the domain's surface net shortwave radiation. ModelE assigns a higher albedo to crop cover than forested or woodland areas, and this effect partly accounts for the increases in reflected shortwave radiation. In the Great Plains, growing season reductions in surface air temperatures are driven by the above-described changes to the turbulent fluxes, and also from overall decline in the shortwave radiation incident at the surface (Fig. 7a).
This latter change results, in part, from an increase in seasonal cloud cover (Fig. 8e), consistent with the increased precipitation. Relative to the NatVeg experiment, there are slight increases in downwelling longwave radiation (Fig. 7c) over the eastern portion of the Great Plains domain. This accompanies reductions in upwelling longwave radiation (Fig. 7d), and these results are consistent with changes in the turbulent fluxes. The Midwest also shows a reduction in net surface shortwave radiation (Fig. 7b). Similar to central Asia, this is primarily driven by enhanced reflected shortwave radiation that results from the higher crop albedos relative to the NatVeg land cover (mostly woodland).

Figure 8 displays the spatial variability in key climatic variables across the three domains (blue boxed areas, averaged for 50 years). These domains all exhibit a significant cooling (Fig. 8a) during the summer growing period, due in part to the increased latent heat fluxes (Fig. 8b) associated with the higher crop LAI. However, a few southern grid boxes within the outlined Great Plains domain show little change or declines in LE. This gradient in the regional response reflects the pattern of LAI differences over the domain, which ranges from increases in the north and east to declines in the central and southern areas (Fig. 2). In each domain, there are statistically significant and prominent declines in sensible heat flux that accompany increases in LE. This repartitioning of the available surface energy is consistent with previous study on agricultural land cover impacts on climate. Significant increases in growing season precipitation are shown in the Great Plains and in southern portions of the central Asian domains [where there are also increases in cloud cover (Fig. 8e) and reductions also occur in incident shortwave radiation (Fig. 7a)]. However, few significant differences in precipitation were found over the Midwest region.

The Great Plains is generally more moisture-limited than the other two domains, and within the region, soil moisture is highly variable (Fig. 9a). The Midwest constitutes a growing region with relatively high soil moisture availability under NatVeg conditions, which suggests that the surface climate may be less responsive to changes in water availability relative to the other domains. In contrast, the Great Plains and central Asia are characterized by transitions between moisturelimited and energy-limited growing zones (oriented from the southwest to the northeast in the Great Plains and from southeast to northwest in central Asia). These transitions strongly influence the background climate state with respect to evaporative regime and hydrologic coupling, particularly during the summer growing season and in winter, when snow-masking effects are prominent. Intensive cropping in the CropSpec 

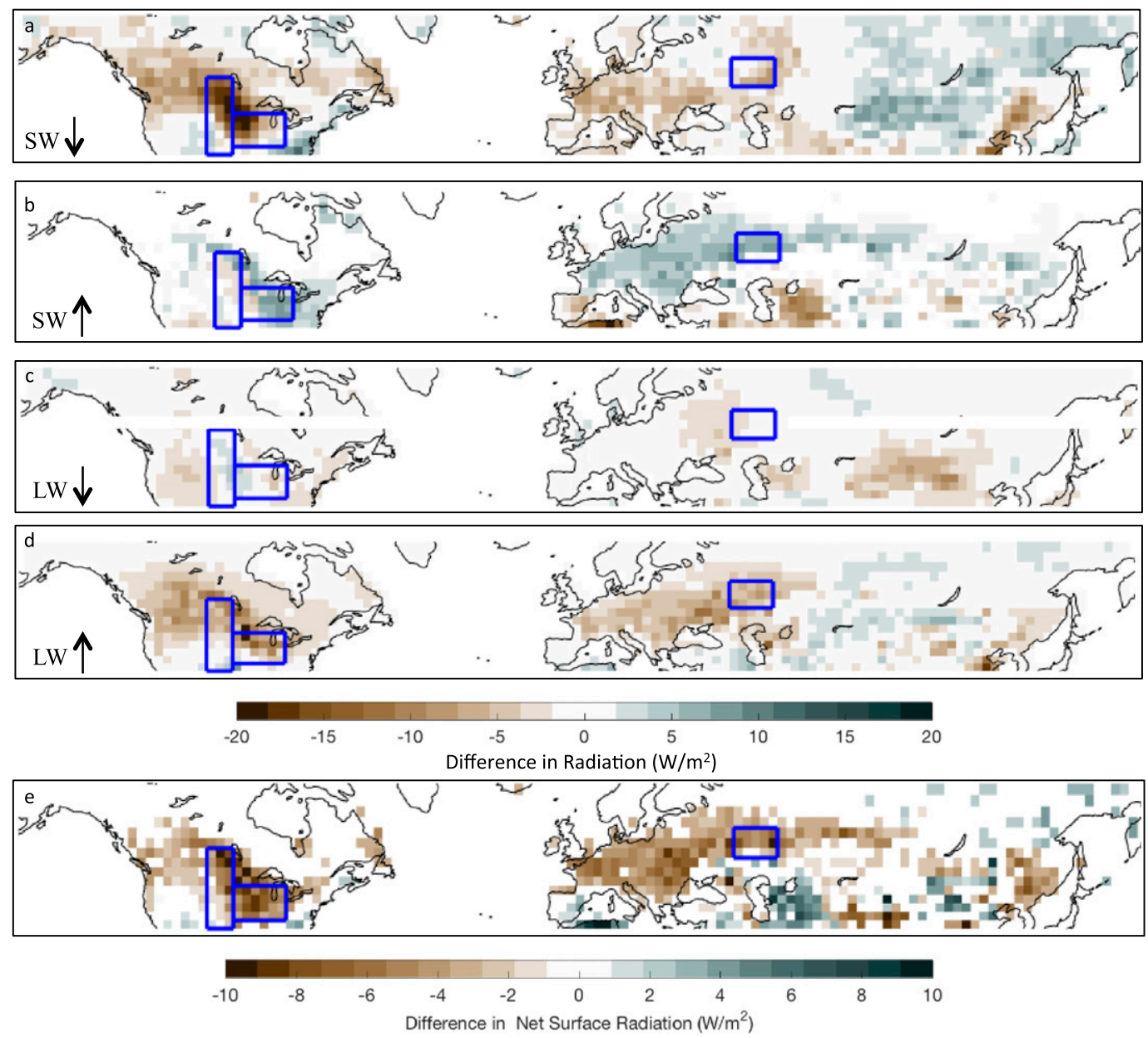

FIG. 7. JJA differences between CropSpec and NatVeg for (a) shortwave radiation incident at the surface, (b) upwelling shortwave radiation from the surface, (c) downwelling longwave radiation, (d) upwelling longwave radiation, and (e) net surface radiation. Only grid boxes with significant differences are shown, following a modified Student's $t$ test unless otherwise specified. Blue boxes highlight the three domains of focus.

experiment enhances the soil moisture across the Great Plains domain (Fig. 9b) but reduces it significantly in the Midwest, with potential consequences (described below) for the regional evaporative regime and hydrologic coupling. Specifically, higher productivity and enhanced precipitation led to increases in regional water availability over the Great Plains, despite the also enhanced ET (Fig. S3). In contrast, there are few significant increases in precipitation over the Midwest and several months show declines. Combined with higher ET during the growing season, this suggests a seasonal "water pumping" effect in the Midwest that serves to reduce the overall available water. These regional differences in the hydrologic response partly stem from the different NatVeg land covers that crops are replacing (e.g., trees in the Midwest vs C3 grasses in the Great Plains). Soil moisture is also reduced in central Asia, although this reduction occurs primarily in the southern portion of the outlined domain. In the northern portions, a few grid boxes display increases in soil moisture, but there is little significant change otherwise.

\section{c. Changes to the hydrologic coupling strength and evaporative regime}

The soil moisture changes resulting from the CropSpec experiment substantially alter the prevailing land surface-atmosphere coupling $[r(\mathrm{LE}, T)]$ across each domain (Fig. 10). In some grid boxes, this results in a conversion between moisture- and energy-limited conditions, indicated by negative and positive correlations, respectively, in Figs. 10a and 10b. While the NatVeg $r$ (LE, $T$ ) shows much variation geographically and seasonally (Fig. 10a), some regional climatological patterns may be highlighted. The Great Plains and Midwest 

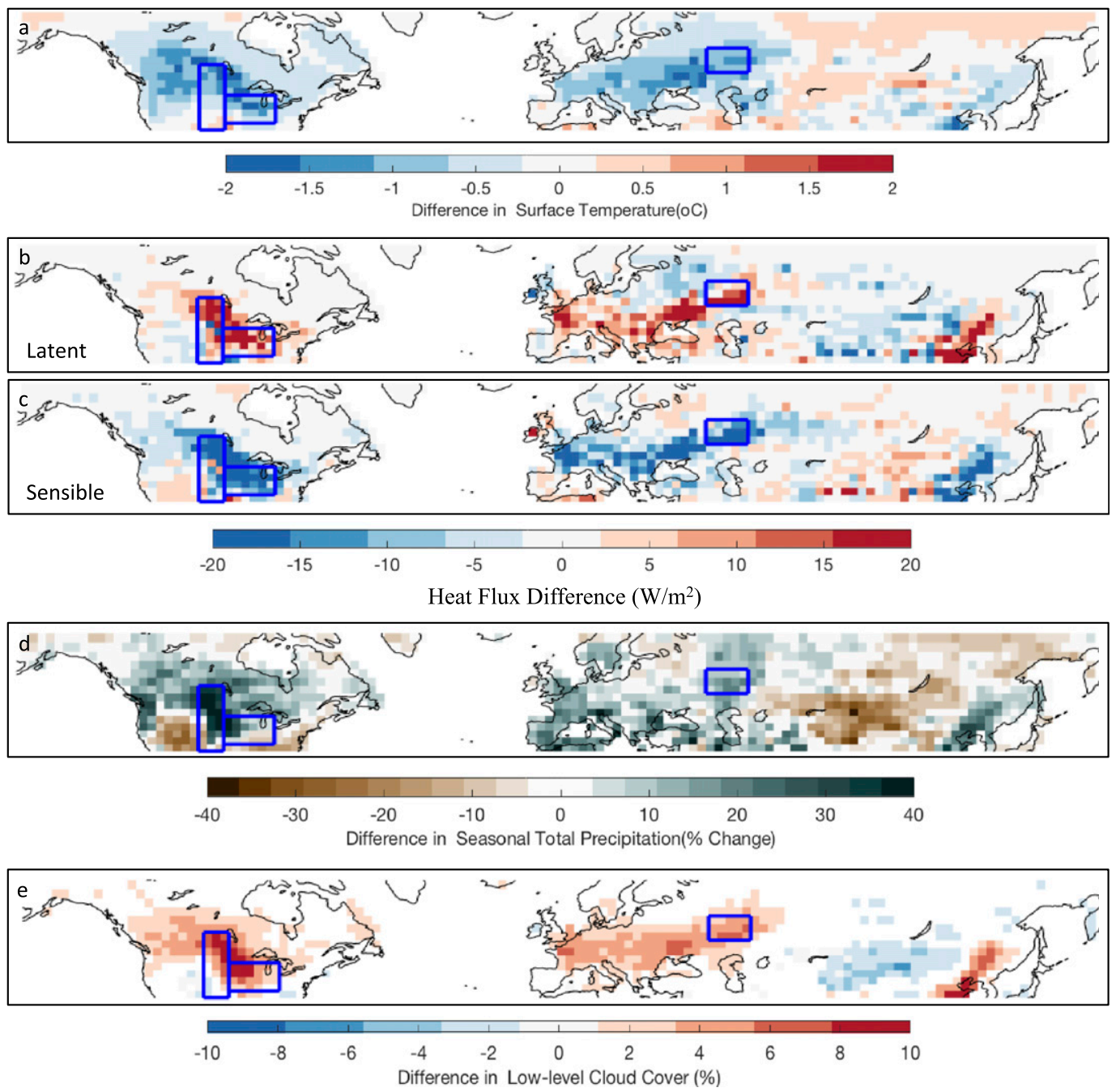

FIG. 8. JJA differences between CropSpec and NatVeg for (a) surface temperature $\left({ }^{\circ} \mathrm{C}\right.$ ), (b) latent heat flux $\left(\mathrm{W} \mathrm{m}^{-2}\right)$, (c) sensible heat flux $\left(\mathrm{W} \mathrm{m}^{-2}\right)$, (d) precipitation (\% change), and (e) low-level cloud cover $(\%)$. Blue boxes highlight the three domains of focus. Only significant differences at the 0.05 level are shaded.

domains are characterized by negative $r(\mathrm{LE}, T)$, in many grid boxes $>-0.4$, indicating more waterlimited evaporative regimes. In these areas, particularly where stronger correlations exist, we would expect additional water availability to result in a relative cooling and weaker hydrologic coupling as moisture limitations to evapotranspiration are reduced. In the Midwest, an area with higher soil moisture under NatVeg conditions, negative correlations are slightly weaker as the surface climate conditions depend less on changes on moisture availability. The CropSpec experiment weakens the correlative strength (i.e., producing less negative correlations; Figs. 10b,c) in both the northern Great Plains and much of the Midwest. In the northern Great Plains, this is due in part to the resultant increases in precipitation and soil moisture, which serve to reduce the dependency of surface air temperature on LE. This shifts the region to less water-limited conditions, thereby diminishing the NatVeg evaporative regime. However, in the southern Great Plains negative correlations, and thus the water-limited evaporative regimes, are slightly enhanced, owing partly to enhanced crop evapotranspiration.

In the Midwest domain, enhanced evapotranspiration and reductions in soil moisture, but no significant change in precipitation, serve to move the region to drier, transitional conditions, in which surface air temperature has little dependency on, or is weakly negative correlated with, latent heat fluxes. Toward the far eastern portion of the Midwest domain, $r(\mathrm{LE}, T)$ changes from slightly negative to moderately positive, transitioning 
Soil Moisture: NatVeg Experiment
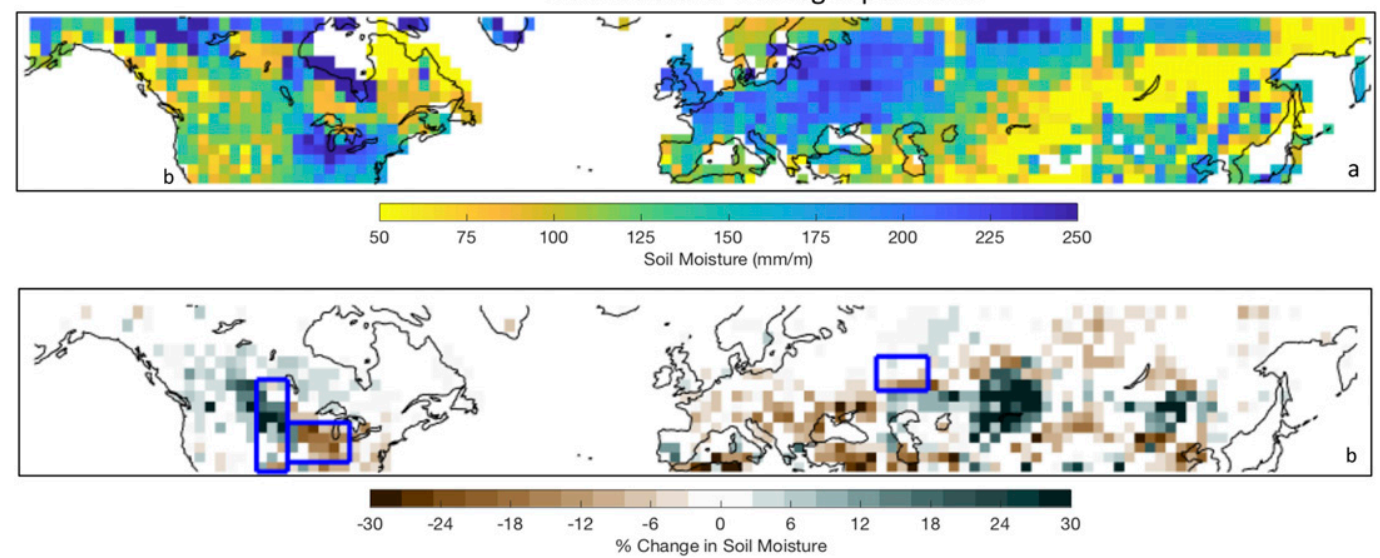

FIG. 9. (a) JJA soil moisture ( $\mathrm{mm}$ ) in the top $50 \mathrm{~cm}$ for the NatVeg experiment. (b) The change in soil moisture (\%) between the CropSpec and NatVeg experiments.

the region from water-limited conditions to a new, more energy-limited, evaporative regime. Facilitating this shift in the far western grid boxes are albedo increases, evidenced by the increased shortwave reflection and surface cooling causing declines in outgoing longwave radiation (Fig. 10d). Less energy available at the surface for partitioning will help to further weaken the negative correlations and move the region to slightly more energy-limited conditions.
In the central Asian domain, a shift in hydrologic coupling, and evaporative regime, is shown between the weak negative $r(\mathrm{LE}, T)$ in the NatVeg experiment to stronger positive correlations in CropSpec-a change toward more energy-limited conditions. This region also represents a transitional zone between water-limited and energy-limited conditions [shown in Fig. 10a as shifts from negative (blue) to positive (red) relationships that occur over the domain]. Agricultural land cover and

JJA Correlation between Latent Heat Flux and Surface Temperature
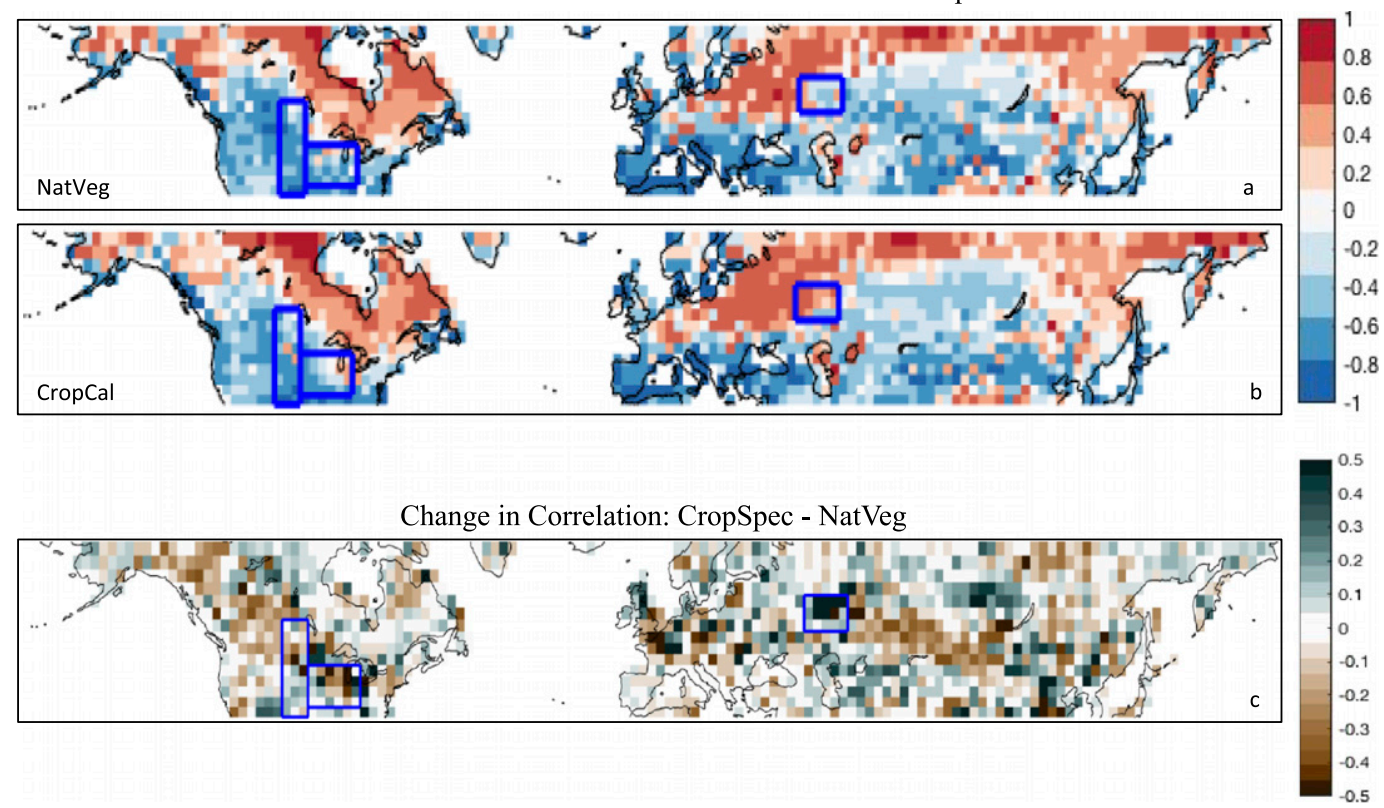

FIG. 10. The JJA Pearson correlation coefficient between interannual latent heat flux and surface temperature for the (a) NatVeg and (b) CropSpec experiments. Blue colors show negative correlations, and red colors indicate positive correlations. (c) Changes in the correlation between the CropSpec and NatVeg experiments. Values have been scaled to show where correlative strength is reduced (brown) and where it is enhanced (teal). 
management appear to shift the boundary of this transitional zone farther east, indicated by the expansion of strong positive $r(\mathrm{LE}, T)$. This expansion occurs despite general increases in LE and reductions in soil moisture across the entire domain.

To reconcile this, we note the substantial geographical variability in the NatVeg $r(\mathrm{LE}, T)$ within the central Asian domain (Fig. 10a). While the soil moisture reductions are substantial and significant, they are confined to the southern part of the domain (Fig. 9b). However, the CropSpec grid boxes that exhibit a change from weak negative to strong positive $r(\mathrm{LE}, T)$ are located in the central and northern portions of domain (Figs. 10b,c). For many of these latter grid boxes, the soil moisture did not change significantly (Fig. 9b) and in some cases increased. This provides a source for enhanced latent heat fluxes and allows the CropSpec transition toward more energylimited conditions in areas that displayed little a priori relationship. In addition, June does exhibit significantly increased precipitation and reduced incident shortwave radiation (Fig. 7a, related to enhanced cloud cover shown in Fig. 8e), and crop albedos are higher than the woodlands they replaced (Fig. 7b), leading to overall declines in net shortwave radiation at the surface. The CropSpec winter period is also characterized by increased snowfall (not shown). Such changes reduce soil moisture losses near the surface, particularly in the springtime, and further facilitate the significant changes evaporative regime and the hydrologic coupling.

\section{d. Comparisons with previous work and regional considerations}

Much uncertainty still exists regarding the regional climate impacts of agricultural land management (Lejeune et al. 2017; Hirsch et al. 2014, 2015). This study is among the first to quantify the impact of agricultural land management on the evaporative regime and hydrologic (land-atmosphere) coupling across important northern midlatitude growing regions. We do so using a novel global representation of agriculture in a state-ofthe-art GCM that resolves maize, wheat, soy, and rice cropping calendars-the climate impacts of which have not been previously considered by GCM experiments, to our knowledge-and their relatively high productivity via observed crop-specific LAI. This representation allows us to move beyond idealized land cover change experiments and generalized crop types employed by a majority of previous GCM studies and uniquely consider the contributions of both modern crop productivity and timing to seasonal surface energy balance and hydrologic (land-atmosphere) coupling in these regions.

In the Great Plains domain, our results show that modern agriculture increases both LE and regional precipitation during the peak growing season. These results are consistent with prior studies across this domain (Pielke et al. 2007; Raddatz 2007; Gameda et al. 2007; Alter et al. 2015), which also highlight precipitation increases due to land cover change. Furthermore, our results also uniquely augment these previous findings by showing how modern agricultural production and timing reduces the land-atmosphere coupling over the northern Great Plains. This occurs through enhanced precipitation in conjunction with cooler temperatures, which serve to buffer soil moisture relative to the NatVeg experiment. Springtime soil evaporation (not shown) is also significantly reduced. As a result of these changes, soil moisture increases year-round in the northern Great Plains domain, thereby decreasing the surface air temperature dependency on LE. However, we also highlight that in the southern Great Plains, there is less change in soil moisture despite similar precipitation increases. In this region, heightened crop ET slightly strengthens the existing moisture-limited evaporative regime (Fig. 10b).

In the Midwest, our findings of reduced growing season surface temperatures compare well with previous studies (Pielke et al. 2011; Mahmood et al. 2014; Diffenbaugh 2009; Mueller et al. 2016; Alter et al. 2017), although the suggested mechanisms vary. For example, more idealized land cover change model experiments result in cooler conditions over the Midwest, partly due to crop albedo changes that limit absorbed shortwave radiation (Diffenbaugh 2009). Our results are consistent with these findings, although these effects predominantly manifest in the eastern Midwest domain. Other regional modeling and observational studies find that intensified agricultural management increases precipitation and decreases surface temperatures across much of the central U.S. growing region (Alter et al. 2017). Likewise, our results also show growing-season precipitation increases specifically in western areas of the Midwest, but eastern areas actually show less significant changes. However, despite this overall enhancement in humidity and cooler temperatures, our results show that the Midwest still exhibits widespread and significant losses in soil moisture throughout the year, and reduced land-atmosphere coupling in much of the domain. Thus, although intensively deployed across the Great Plains and Midwest, we show that modern crop management can have widely varying impacts on the evaporative regime and background climate across these important midlatitude growing regions. This result is highly relevant to considerations of the regional climate change mitigation potential of agricultural land management (Hirsch et al. 2017; Seneviratne et al. 2018), particularly with respect to intensive, highly productive cropping systems with significant input demands. 
We note, however, that agricultural technology trends, particularly with respect to irrigation, could further buffer against regional temperature increases and could also be a major driver of the recent, regionally observed cooling over the central United States (Alter et al. 2017; Mueller et al. 2016). Indeed, irrigation management has played a pivotal role in agricultural intensification and increased production, particularly across the southern Great Plains domain. More recently, irrigation has expanded to (albeit limited) areas across the more humid southeastern U.S. states and portions of the Midwest, particularly Nebraska (USDA 2014). Irrigated areas may induce cooling either by enhancing latent heat fluxes or via interactions with precipitation and regional circulation processes (Pei et al. 2016; Mueller et al. 2017; Bonfils and Lobell 2007). Both observational and model studies have attributed higher rainfall over the Great Plains and (western) Midwest to intensified irrigation (Alter et al. 2015; Pei et al. 2016). Additionally, the Midwestern domain has exhibited a summertime "warming hole" over the twentieth century, as well as attenuated heat extremes, which cannot be explained by natural climate variability alone (Partridge et al. 2018; Alter et al. 2017). Further exploration has shown that these responses may be driven by agricultural intensification and increased irrigation (Partridge et al. 2018; Mueller et al. 2016; Alter et al. 2017). Nebraska, in particular, has exhibited a significant cooling that has been closely associated with intensive irrigation (Mueller et al. 2016). More generally, the regional and global climate impacts (i.e., land surface cooling) of irrigation have been deemed significant enough to be recommended for inclusion in the suite of historical climate forcings commonly run by coordinated climate model intercomparisons (Cook et al. 2014).

With respect to the results presented herein, large amounts of water added to the soil surface via irrigation could further reduce the hydrologic coupling across water-limited areas in these domains, thereby amplifying our results and supporting our findings. It is also possible that added irrigation may further modulate rainfall changes in the Great Plains and mitigate soil moisture declines if introduced across the Midwest. Given these considerations and the demonstrated importance of irrigation as an anthropogenic forcing, it is critical that future iterations of these experiments should also include regionally representative irrigation applications and timing.

Our experiment indicates that even with negligible changes in rainfall, soil moisture declines associated with land cover change can significantly alter the Midwestern background climate state and evaporative regime. An east-west dipole-like pattern of hydrologic coupling results from the imposed agricultural representation that was not present under natural vegetation conditions. In some grid boxes, the significant loss of soil moisture may actually reduce the dependency of surface air temperature on the partitioning between the turbulent fluxes. Much of the Midwestern region exhibits a strong increase in reflected shortwave radiation, which forces the regional background climate to shift toward a weak or negligible hydrologic coupling that is more characteristic of arid conditions (extreme cases of such conditions are found across the desert regions of northern Africa and the Arabian Peninsula).

\section{Conclusions}

We assessed how intensive crop cover and management impact the hydrologic coupling, evaporative regime, and background climate in important $\mathrm{NH}$ midlatitude growing regions that lie in transition zones between moistureand energy-limited conditions.

Results show that in the northern Great Plains and much of the U.S. Midwest the strength of the waterlimited evaporative regime is weakened during the growing season as a result of agricultural land use. In the northern Great Plains, this is largely due to regional rainfall increases that accompanied higher LAI, representing modern crop productivity, despite higher evapotranspiration. However, these LAI increases do slightly enhance the water-limited evaporative regime in the southern Great Plains and western areas of the Midwest. More broadly across the Midwest, reduced hydrologic coupling results mainly from higher crop latent heat fluxes and albedos relative to woodland and forested areas, which reduces net surface shortwave radiation and the energy available at the surface for partitioning between the turbulent fluxes. As such, the coupling in the Midwest is weakened despite losses in soil moisture. In central Asia, a combination of albedo changes, enhanced cloud cover, and increased winter/spring precipitation serve to transition much of the region toward strongly energy-limited conditions.

The reduced hydrologic coupling in areas that were moisture limited under NatVeg conditions suggests that agriculturally enhanced soil moisture could modulate air temperature changes in favor of relatively cooler conditions during the growing season. This change in sensitivity is pertinent to these heavily cultivated regions, particularly during the growing season when crops are susceptible to temperature extremes. This is especially true in areas that experienced heightened growing season precipitation as a result of intensive agriculture. However, the prevailing responses can be quite spatially heterogeneous and are highly dependent on the a priori 
surface conditions. Furthermore, these sensitivity experiments omit other critical crop and management components-particularly related to agricultural soils and erodability, differences in crop root structure relative to natural vegetation, and irrigation - that may amplify the results in the Great Plains and have other important climate interactions. Furthermore, the Midwest and central Asia experience simulated soil moisture losses and more energy-limited conditions, which may demand supplemental management for representative simulations of crop growth.

"Natural vegetation" was used for these sensitivity experiments as a basis for quantifying the hydroclimate impacts of modern intensive agriculture. However, it is important to note that there can be variability in what constitutes so-called natural vegetation, which can range from potential vegetation simulations to varying classifications of existing land cover types (e.g., the grouping of crops and pasture grasses). Coupled with this, there is also substantial variation in different land covers' LAI between products (e.g., Koster et al. 2004; Zhao et al. 2013), which is important because responses to the agricultural land forcing will be highly sensitive to the a priori land cover. When mapped onto our Ent PFTs, the MODIS product provided relatively low LAIs for natural vegetation (compared to other products), as these land covers were those remaining after crops and pasture had been removed. To assess the implications of these MODIS values, we ran additional sensitivity experiments (not shown) artificially raising the maximum LAIs for regionally prominent natural PFTs to values no less than 1 for grasses, and 2 for other vegetation types. We found a slight reduction in the magnitude of the response over the Great Plains, owing to smaller changes in latent heat fluxes, but overall no substantial changes from our results and findings presented herein.

However, more work is needed to compare the impacts of agriculture across different representations of natural vegetation and a priori surface conditions, particularly as "real world" land transitions often occur on previously modified land (e.g., conversions between cropping systems, improved technologies, or other land uses). To facilitate this, better GCM representation of current land uses and hydrologic coupling is needed to assess the impacts of potential transitions between a variety of alternative land cover and management scenarios. Additionally, our future work will iterate on these experiments to evaluate how agricultural land management interacts with anthropogenic GHG and other forcings to further impact regional climates. Including additional forcings can introduce more complicated interactions and confounding factors, such as
$\left[\mathrm{CO}_{2}\right]$ fertilization effects, higher regional surface temperatures, and changes in general circulation, precipitation patterns, and extremes. Such inclusions will enhance the relevance of this work and target emerging questions related to the mitigation of regional climate impacts via agricultural land management. Future work should also consider more comprehensive metrics of land surface coupling, such as those utilized by the Global Land-Atmosphere Coupling Experiment project (Koster et al. 2006; Hirsch et al. 2015), which consider soil moisture memory and serve to further the process-level understanding.

Acknowledgments. All data used in this study are publically accessible. Results from ModelE simulations are available upon written request to the corresponding author. C. Montes conducted this work through an appointment with the NASA Postdoctoral Program at the Goddard Institute for Space Studies, administered by Universities Space Research Association through a contract with NASA. Resources supporting this work were provided by the NASA High-End Computing (HEC) Program through [the NASA Advanced Supercomputing (NAS) Division at Ames Research Center and] the NASA Center for Climate Simulation (NCCS) at Goddard Space Flight Center. B.I. Cook and M.J. Puma both supported by the NASA Modeling, Analysis, and Prediction program, including NASA Grant NASA 80NSSC17K0265. The authors would also like to acknowledge and thank Dr. Larissa Nazarenko and Dr. Max Kelley for their overall contributions to the GISS model development effort and their contributions to model functionalities used herein.

\section{REFERENCES}

Abramopoulos, F., C. Rosenzweig, and B. Choudhury, 1988: Improved ground hydrology calculations for global climate models (GCMs): Soil water movement and evapotranspiration. J. Climate, 1, 921-941, https://doi.org/10.1175/1520-0442 (1988)001<0921:IGHCFG > 2.0.CO;2.

Alessandri, A., and A. Navarra, 2008: On the coupling between vegetation and rainfall inter-annual anomalies: Possible contributions to seasonal rainfall predictability over land areas. Geophys. Res. Lett., 35, L02718, https://doi.org/10.1029/ $2007 \mathrm{GL} 032415$.

Alter, R. E., Y. Fan, B. R. Lintner, and C. P. Weaver, 2015: Observational evidence that Great Plains irrigation has enhanced summer precipitation intensity and totals in the Midwestern United States. J. Hydrometeor., 16, 1717-1735, https://doi.org/ 10.1175/JHM-D-14-0115.1.

, H. C. Douglas, J. M. Winter, and E. A. B. Eltahir, 2017: Twentieth century regional climate change in the central United States attributed to agricultural intensification. Geophys. Res. Lett., 45, 1586-1594, https://doi.org/10.1002/2017GL075604. 
Bonfils, C., and D. Lobell, 2007: Empirical evidence for a recent slowdown in irrigation-induced cooling. Proc. Natl. Acad. Sci. USA, 104, 13 582-13 587, https://doi.org/10.1073/pnas.0700144104.

Cook, B. I., S. P. Shukla, M. J. Puma, and L. S. Nazarenko, 2014: Irrigation as an historical climate forcing. Climate Dyn., 44, 1715-1730, https://doi.org/10.1007/s00382-014-2204-7.

de Noblet-Ducoudré, N., and Coauthors, 2012: Determining robust impacts of land-use-induced land cover changes on surface climate over North America and Eurasia: Results from the first set of LUCID experiments. J. Climate, 25, 3261-3281, https://doi.org/10.1175/JCLI-D-11-00338.1.

Diffenbaugh, N. S., 2009: Influence of modern land cover on the climate of the United States. Climate Dyn., 33, 945-958, https://doi.org/10.1007/s00382-009-0566-z.

Dirmeyer, P. A., X. Gao, M. Zhao, Z. Guo, T. Oki, and N. Hanasaki, 2006: GSWP-2: Multimodel analysis and implications for our perception of the land surface. Bull. Amer. Meteor. Soc., 87, 1381-1397, https://doi.org/10.1175/ BAMS-87-10-1381.

Erisman, J. W., M. A. Sutton, J. Galloway, Z. Klimont, and W. Winiwarter, 2008: How a century of ammonia synthesis changed the world. Nat. Geosci., 1, 636-639, https://doi.org/ 10.1038/ngeo325.

Eyring, V., S. Bony, G. A. Meehl, C. Senior, B. Stevens, R. J. Stouffer, and K. E. Taylor, 2016: Overview of the Coupled Model Intercomparison Project Phase 6 (CMIP6) experimental design and organisation. Geosci. Model Dev., 9, 1937-1958, https://doi.org/ 10.5194/gmd-9-1937-2016.

Foley, J. A., and Coauthors, 2011: Solutions for a cultivated planet. Nature, 478, 337-342, https://doi.org/10.1038/nature10452.

Friedl, M. A., D. Sulla-Menashe, B. Tan, A. Schneider, N. Ramankutty, A. Sibley, and X. Huang, 2010: MODIS Collection 5 global land cover: Algorithm refinements and characterization of new datasets. Remote Sens. Environ., 114, 168-182, https://doi.org/ 10.1016/j.rse.2009.08.016.

Friend, A. D., and N. Y. Kiang, 2005: Land surface model development for the GISS GCM: Effects of improved canopy physiology on simulated climate. J. Climate, 18, 2883-2902, https://doi.org/10.1175/JCLI3425.1.

Gameda, S., B. Qian, C. A. Campbell, and R. L. Desjardins, 2007: Climatic trends associated with summerfallow in the Canadian Prairies. Agric. For. Meteor., 142, 170-185, https://doi.org/ 10.1016/j.agrformet.2006.03.026.

Ge, J., 2010: MODIS observed impacts of intensive agriculture on surface temperature in the southern Great Plains. Int. J. Climatol., 30, 1994-2003, https://doi.org/10.1002/joc.2093.

Georgescu, M., D. B. Lobell, and C. B. Field, 2011: Direct climate effects of perennial bioenergy crops in the United States. Proc. Natl. Acad. Sci. USA, 108, 4307-4312, https://doi.org/10.1073/ pnas.1008779108.

Gray, J. M., S. Frolking, E. A. Kort, D. K. Ray, C. J. Kucharik, N. Ramankutty, and M. A. Friedl, 2014: Direct human influence on atmospheric $\mathrm{CO}_{2}$ seasonality from increased cropland productivity. Nature, 515, 398-401, https://doi.org/10.1038/ nature13957.

Hansen, J., G. Russell, D. Rind, P. Stone, A. Lacis, S. Lebedeff, R. Ruedy, and L. Travis, 1983: Efficient three-dimensional global models for climate studies: Models I and II. Mon. Wea. Rev., 111, 609-662, https://doi.org/10.1175/1520-0493(1983)111<0609: ETDGMF $>2.0 . \mathrm{CO} ; 2$.

Harris, I., P. D. Jones, T. J. Osborn, and D. H. Lister, 2014: Updated high-resolution grids of monthly climatic observations-The
CRU TS3.10 dataset. Int. J. Climatol., 34, 623-642, https:// doi.org/10.1002/joc.3711.

Hirsch, A. L., A. J. Pitman, and J. Kala, 2014: The role of land cover change in modulating the soil moisture-temperature landatmosphere coupling strength over Australia. Geophys. Res. Lett., 41, 5883-5890, https://doi.org/10.1002/2014GL061179.

, R. Lorenz, and M.G. Donat, 2015: Modulation of land-use change impacts on temperature extremes via landatmosphere coupling over Australia. Earth Interact., 19 https://doi.org/10.1175/EI-D-15-0011.1.

_ , M. Wilhelm, E. L. Davin, W. Thiery, and S. I. Seneviratne, 2017: Can climate-effective land management reduce regional warming? J. Geophys. Res., 122, 2269-2288, https://oi.org/ 10.1002/2016JD026125.

Hurtt, G. C., and Coauthors, 2011: Harmonization of land-use scenarios for the period 1500-2100: 600 years of global gridded annual land-use transitions, wood harvest, and resulting secondary lands. Climatic Change, 109, 117-161, https://doi.org/ 10.1007/s10584-011-0153-2.

Kim, Y., P. R. Moorcroft, I. Aleinov, M. J. Puma, and N. Y. Kiang, 2015: Variability of phenology and fluxes of water and carbon with observed and simulated soil moisture in the Ent Terrestrial Biosphere Model (Ent TBM version 1.0.1.0.0). Geosci. Model Dev., 8, 3837-3865, https://doi.org/10.5194/ gmd-8-3837-2015.

Koster, R. D., and Coauthors, 2004: Realistic initialization of land surface states: Impacts on subseasonal forecast skill. J. Hydrometeor., 5, 1049-1063, https://doi.org/10.1175/JHM-387.1. , and Coauthors, 2006: GLACE: The Global Land-Atmosphere Coupling Experiment. Part I: Overview. J. Hydrometeor., 7, 590-610, https://doi.org/10.1175/JHM510.1.

_ , S. D. Schubert, and M. J. Suarez, 2009: Analyzing the concurrence of meteorological droughts and warm periods, with implications for the determination of evaporative regime. J. Climate, 22, 3331-3341, https://doi.org/10.1175/ 2008JCLI2718.1.

Lejeune, Q., S. I. Seneviratne, and E. L. Davin, 2017: Historical land-cover change impacts on climate: Comparative assessment of LUCID and CMIP5 multimodel experiments. J. Climate, 30, 1439-1459, https://doi.org/10.1175/ JCLI-D-16-0213.1.

Luyssaert, S., and Coauthors, 2014: Land management and landcover change have impacts of similar magnitude on surface temperature. Nat. Climate Change, 4, 389-393, https://doi.org/ 10.1038/nclimate2196.

Mahmood, R., and Coauthors, 2014: Land cover changes and their biogeophysical effects on climate. Int. J. Climatol., 34, 929-953, https://doi.org/10.1002/joc.3736.

Matthews, E., 1983: Global vegetation and land use: New highresolution data bases for climate studies. J. Climate Appl. Meteor., 22,474-487, https://doi.org/10.1175/1520-0450(1983)022<0474: GVALUN $>2.0 . \mathrm{CO} ; 2$

McDermid, S. S., L. O. Mearns, and A. C. Ruane, 2017: Representing agriculture in Earth system models: Approaches and priorities for development. J. Adv. Model. Earth Syst., 9, 2230-2265, https://doi.org/10.1002/2016MS000749.

Miller, R. L., and Coauthors, 2014: CMIP5 historical simulations (1850-2012) with GISSModelE2. J. Adv. Model. Earth Syst., 6, 441-477, https://doi.org/10.1002/2013MS000266.

Monfreda, C., N. Ramankutty, and J. A. Foley, 2008: Farming the planet: 2. Geographic distribution of crop areas, yields, physiological types, and net primary production in the year 2000 
Global Biogeochem. Cycles, 22, GB1022, https://doi.org/10.1029/ 2007 GB002947.

Mueller, N. D., J. S. Gerber, M. Johnston, D. K. Ray, N. Ramankutty, and J. A. Foley, 2012: Closing yield gaps through nutrient and water management. Nature, 490, 254-257, https://doi.org/10.1038/nature11420.

- E. E. Butler, K. A. McKinnon, A. Rhines, M. Tingley, N. M. Holbrook, and P. Huybers, 2016: Cooling of U.S. Midwest summer temperature extremes from cropland intensification. Nat. Climate Change, 6, 317-322, https://doi.org/ 10.1038/nclimate2825.

, A. Rhines, E. E. Butler, D. K. Ray, S. Siebert, N. M. Holbrook, and P. Huybers, 2017: Global relationships between cropland intensification and summer temperature extremes over the last 50 years. J. Climate, 30, 7505-7528, https://doi.org/ 10.1175/JCLI-D-17-0096.1.

Nair, U. S., Y. Wu, J. Kala, T. J. Lyons, R. A. Pielke Sr., and J. M. Hacker, 2011: The role of land use change on the development and evolution of the west coast trough, convective clouds, and precipitation in southwest Australia. J. Geophys. Res., 116, D07103, https://doi.org/10.1029/2010JD014950.

Nazarenko, L., and Coauthors, 2015: Future climate change under RCP emission scenarios with GISS ModelE2. J. Adv. Model. Earth Syst., 7, 244-267, https://doi.org/10.1002/ 2014MS000403.

Partridge, T. F., J. M. Winter, E. C. Osterberg, D. W. Hyndman, A. D. Kendall, and F. J. Magilligan, 2018: Spatially distinct seasonal patterns and forcings of the U.S. warming hole. Geophys. Res. Lett., 45, 2055-2063, https://doi.org/10.1002/2017GL076463.

Pei, L., N. Moore, S. Zhong, A. D. Kendall, Z. Gao, and D. W. Hyndman, 2016: Effects of irrigation on summer precipitation over the United States. J. Climate, 29, 3541-3558, https://doi. org/10.1175/JCLI-D-15-0337.1.

Pielke, R., Jr., G. Prins, S. Rayner, and D. Sarewitz, 2007: Climate change 2007: Lifting the taboo on adaptation. Nature, $\mathbf{4 4 5}$, 597-598, https://doi.org/10.1038/445597a.

_- , and Coauthors, 2011: Land use/land cover changes and climate: Modeling analysis and observational evidence. Wiley Interdiscip. Rev.: Climate Change, 2, 828-850, https://doi.org/ 10.1002/wcc.144.

Pitman, A. J., and Coauthors, 2009: Uncertainties in climate responses to past land cover change: First results from the LUCID intercomparison study. Geophys. Res. Lett., 36, L14814, https:// doi.org/10.1029/2009GL039076.

_ , F. B. Avila, G. Abramowitz, Y. P. Wang, S. J. Phipps, and N. de Noblet-Ducoudré, 2011: Importance of background climate in determining impact of land-cover change on regional climate. Nat. Climate Change, 1, 472-475, https://doi.org/ 10.1038/nclimate1294.

Pongratz, J., C. Reick, T. Raddatz, and M. Claussen, 2008: Biogeophysical effects of anthropogenic land cover change during the last millennium. 1 p., accessed 8 June 2016 , http://static.egu.eu/media/awards/union-osp-award/2008/julia_ pongratz.pdf.

Raddatz, R. L., 2007: Evidence for the influence of agriculture on weather and climate through the transformation and management of vegetation: Illustrated by examples from the Canadian Prairies. Agric. For. Meteor., 142, 186-202, https://doi.org/ 10.1016/j.agrformet.2006.08.022.

Ramankutty, N., J. A. Foley, J. Norman, and K. McSweeney, 2002: The global distribution of cultivable lands: Current patterns and sensitivity to possible climate change. Global
Ecol. Biogeogr., 11, 377-392, https://doi.org/10.1046/ j.1466-822x.2002.00294.x.

—_ C. Delire, and P. Snyder, 2006: Feedbacks between agriculture and climate: An illustration of the potential unintended consequences of human land use activities. Global Planet. Change, 54, 79-93, https://doi.org/10.1016/ j.gloplacha.2005.10.005.

Ray, D. K., N. D. Mueller, P. C. West, and J. A. Foley, 2013: Yield trends are insufficient to double global crop production by 2050. PLOS ONE, 8, e66428, https://doi.org/10.1371/journal. pone. 0066428

_ J. S. Gerber, G. K. MacDonald, and P. C. West, 2015: Climate variation explains a third of global crop yield variability. Nat. Commun., 6, 5989, https://doi.org/10.1038/ncomms6989.

Rosenzweig, C., and F. Abramopoulos, 1997: Land-surface model development for the GISS GCM. J. Climate, 10, 2040-2054, https://doi.org/10.1175/1520-0442(1997)010<2040: LSMDFT $>2.0 . \mathrm{CO} ; 2$.

Ryu, Y., D. D. Baldocchi, S. Ma, and T. Hehn, 2008: Interannual variability of evapotranspiration and energy exchange over an annual grassland in California. J. Geophys. Res., 113, D09104, https://doi.org/10.1029/2007JD009263.

Sacks, W. J., D. Deryng, J. A. Foley, and N. Ramankutty, 2010: Crop planting dates: An analysis of global patterns. Global Ecol. Biogeogr., 19, 607-620, https://doi.org/10.1111/ j.1466-8238.2010.00551.x.

Schmidt, G. A., and Coauthors, 2014: Configuration and assessment of the GISS ModelE2 contributions to the CMIP5 archive. J. Adv. Model. Earth Syst., 6, 141-184, https://doi.org/ 10.1002/2013MS000265.

Schneider, U., A. Becker, P. Finger, A. Meyer-Christoffer, M. Ziese, and B. Rudolf, 2014: GPCC's new land surface precipitation climatology based on quality-controlled in situ data and its role in quantifying the global water cycle. Theor. Appl. Climatol., 115, 15-40, https://doi.org/10.1007/ s00704-013-0860-x.

Seneviratne, S. I., D. Lüthi, M. Litschi, and C. Schär, 2006: Landatmosphere coupling and climate change in Europe. Nature, 443, 205-209, https://doi.org/10.1038/nature05095.

, T. Corti, E. L. Davin, M. Hirschi, E. B. Jaeger, I. Lehner, B. Orlowsky, and A. J. Teuling, 2010: Investigating soil moisture-climate interactions in a changing climate: A review. Earth Sci. Rev., 99, 125-161, https://doi.org/10.1016/ j.earscirev.2010.02.004

- and Coauthors, 2018: Land radiative management as contributor to regional-scale climate adaptation and mitigation. Nat. Geosci., 11, 88-96, https://doi.org/10.1038/ s41561-017-0057-5.

Simard, M., N. Pinto, J. B. Fisher, and A. Baccini, 2011: Mapping forest canopy height globally with spaceborne lidar. J. Geophys. Res. Biogeosci., 116, G04021, https://doi.org/ 10.1029/2011JG001708.

Smith, P., and Coauthors, 2014: Agriculture, Forestry and Other Land Use (AFOLU). Climate Change 2014: Mitigation of Climate Change, O. Edenhofer et al., Eds., Cambridge University Press, 811-922.

Spitters, C. J. T., H. A. J. M. Toussaint, and J. Goudriaan, 1986: Separating the diffuse and direct component of global radiation and its implications for modeling canopy photosynthesis Part I. Components of incoming radiation. Agric. For. Meteor., 38, 217-229, https://doi.org/10.1016/0168-1923(86)90060-2.

Thiery, W., E. L. Davin, D. M. Lawrence, A. L. Hirsch, M. Hauser, and S. I. Seneviratne, 2017: Present-day irrigation mitigates 
heat extremes. J. Geophys. Res., 122, 1403-1422, https:// doi.org/10.1002/2016JD025740.

Tian, Y., and Coauthors, 2002a: Multiscale analysis and validation of the MODIS LAI product: I. Uncertainty assessment. Remote Sens. Environ., 83, 414-430, https://doi.org/10.1016/ S0034-4257(02)00047-0.

, and Coauthors, 2002b: Multiscale analysis and validation of the MODIS LAI product: II. Sampling strategy. Remote Sens. Environ., 83, 431-441, https://doi.org/10.1016/S0034-4257(02) 00058-5.

Tubiello, F. N., and Coauthors, 2014: Agriculture, Forestry and Other Land Use Emissions by Sources and Removals by Sinks. FAO Statistics Division Working Paper Series ESS/ 14-02, Food and Agriculture Organization, 75 pp., http:// www.fao.org/docrep/019/i3671e/i3671e.pdf.

USDA, 2014: 2013 Census of Agriculture: Farm and Ranch Irrigation Survey. USDA, 266 pp., https://www.nass.usda.gov/ Publications/AgCensus/2012/Online_Resources/Farm_and_ Ranch_Irrigation_Survey/.

Yang, W., and Coauthors, 2006: MODIS leaf area index products: from validation to algorithm improvement. IEEE Trans. Geosci. Remote Sens., 44, 1885-1898, https://doi.org/10.1109/ TGRS.2006.871215.
Yuan, H., Y. Dai, Z. Xiao, D. Ji, and W. Shangguan, 2011: Reprocessing the MODIS Leaf Area Index products for land surface and climate modelling. Remote Sens. Environ., 115, 1171-1187, https://doi.org/10.1016/j.rse.2011.01.001.

Zeng, N., F. Zhao, G. J. Collatz, E. Kalnay, R. J. Salawitch, T. O. West, and L. Guanter, 2014: Agricultural Green Revolution as a driver of increasing atmospheric $\mathrm{CO}_{2}$ seasonal amplitude. Nature, 515, 394-397, https://doi.org/10.1038/nature13893.

Zhao, X., and Coauthors, 2013: The Global Land Surface Satellite (GLASS) remote sensing data processing system and products. Remote Sens., 5, 2436-2450, https://doi.org/10.3390/ rs5052436.

Zhu, Z., and Coauthors, 2013: Global data sets of vegetation leaf area index (LAI) $3 \mathrm{~g}$ and fraction of photosynthetically active radiation (FPAR) $3 \mathrm{~g}$ derived from global inventory modeling and mapping studies (GIMMS) normalized difference vegetation index (NDVI3g) for the period 1981 to 2011. Remote Sens., 5, 927-948, https://doi.org/10.3390/rs5020927.

Zwiers, F. W., and H. von Storch, 1995: Taking serial correlation into account in tests of the mean. J. Climate, 8, 336-351, https://doi.org/10.1175/1520-0442(1995)008<0336: TSCIAI $>2.0 . \mathrm{CO} ; 2$. 